\title{
Spatial and Temporal Properties of Cone Signals in Alert Macaque Primary Visual Cortex
}

\author{
Bevil R. Conway ${ }^{1,2}$ and Margaret S. Livingstone ${ }^{1}$ \\ ${ }^{1}$ Department of Neurobiology, Harvard Medical School, Boston, Massachusetts 02115, and ${ }^{2}$ Wellesley College, Wellesley, Massachusetts 02481
}

\begin{abstract}
Neurons in the lateral geniculate nucleus cannot perform the spatial color calculations necessary for color contrast and color constancy. Under neutral-adapting conditions, we mapped the cone inputs (L, M, and S) to 83 cone-opponent cells representing the central visual field of the next stage of visual processing, primary visual cortex (V1), to determine how the color signals are spatially transformed. Cone-opponent cells, constituting $\sim 10 \%$ of V1 cells, formed two populations, red-green ( $\mathrm{Ls} \mathrm{M} ; 66$ of 83 ) and blue-yellow ( $\mathrm{S}$ vs L $+\mathrm{M}$; 17 of 83). Many cone-opponent cells (48 of 83) were double-opponent, with circular receptive-field centers and crescent-shaped surrounds $\left(0.63^{\circ}\right.$ offset $)$ that had opposite chromatic tuning to the centers and a time-to-peak $11 \mathrm{~ms}$ later than the centers. The remaining cone-opponent cells were either spatially opponent in only one cone system ( 20 of 83 ) or lacked spatial opponency ( 15 of 83$)$. Cells lacking spatial opponency had smaller receptive fields $\left(0.5-0.7^{\circ}\right)$ than spatial-opponent cell centers $\left(\sim 1^{\circ}\right)$. We found that red-green cells received S-cone input, which aligned with $\mathrm{M}$ input, and, unlike blue-yellow cells, red-green cells gave push-pull responses: receptivefield centers of red-ON cells were excited by both L increments (bright red) and $\mathrm{M}$ decrements (dark red) and were suppressed by both L decrements (dark green) and M increments (bright green). Excitatory responses to decrements were slightly larger than to increments, which may account for the lower detection and discrimination thresholds of decrements shown psychophysically. By virtue of their specialized receptive fields, the neurons described here spatially transform the cone signals and represent the first stage in the visual system at which spatially opponent color calculations are made.
\end{abstract}

Key words: receptive-field; primate; V1; color; double-opponent; color constancy

\section{Introduction}

Color perception is achieved by comparing the responses of the three cone types (L, M, and S; loosely red, green, and blue). This calculation is typified by retinal blue-ON neurons, which are excited by S-cone activity and suppressed by $(\mathrm{L}+\mathrm{M})$-cone activity (Dacey and Lee, 1994). Blue-ON neurons likely connect to blue-yellow type II cells in the lateral geniculate nucleus (LGN) (Martin et al., 1997). Type I neurons in the LGN also show cone opponency but between $\mathrm{L}$ and $\mathrm{M}$ cones, so they are often called red-green (De Valois et al., 1958). It remains unclear how the cortex uses these signals to make spatial color comparisons, a step required for color contrast and color constancy (Land, 1977).

Spatially opponent color calculations are not achieved by the LGN. Type II cells do not have center-surround receptive fields (Wiesel and Hubel, 1966; Chichilnisky and Baylor, 1999), as would be required, and the opponent systems of type I cells are spatially opponent in luminance, not color (Wiesel and Hubel,

Received May 16, 2006; revised Sept. 7, 2006; accepted Sept. 13, 2006.

B.R.C. was supported by the Harvard Society of Fellows, the Alexander von Humboldt Foundation, and Alexander Rehding. David Freeman programmed the stimuli. Tamara Chuprina provided animal care. Doris Tsao, Winrich Freiwald, and Christopher Pack helped with the analysis programs. We are grateful to Greg Horwitz, Vincent Billock, Doris Tsao, Winrich Friewald, Camilo Libedinsky, Piers Howe, and Sebastian Moeller, who gave useful comments on this manuscript, and to Greg Horwitz and E. J. Chichilnisky for communicating unpublished observations. B.R.C. is grateful to David Hubel for mentorship throughout the project.

Correspondence should be addressed to Bevil R. Conway, Department of Neurobiology, Harvard Medical School, Boston, MA 02115. E-mail: bconway@hms.harvard.edu.

DOI:10.1523/JNEUROSCI.2091-06.2006

Copyright $\odot 2006$ Society for Neuroscience $\quad$ 0270-6474/06/2610826-21\$15.00/0
1966) (see Fig. 1A). The opponent systems of a given type 1 cell are actually centered at the same location (Reid and Shapley, 2002), a configuration captured by a difference of Gaussians (Rodieck, 1965): the center is narrower but stronger than the surround (see Fig. $1 A$ ).

Spatially opponent color calculations could be performed by receptive fields that, like type I cells, can also be represented as a difference of Gaussians (see Fig. 1B, model 1) (Lennie and D'Zmura, 1988). However, the inputs required by this model would need to have receptive fields not seen in type 1 cells or any LGN cell: an L+ center would need to be accompanied by an Lsurround rather than an $\mathrm{M}-$ surround (Hubel and Livingstone, 1990a).

Billock (1991) has proposed an alternative color-contrast model that combines inputs from many type I cells, low-pass filtering the luminance signal of each input while retaining its chromatic opponency (see Fig. $1 B$, model 2). The model samples one pool of type 1 cells for the center and one for the surround, a "difference of offset Gaussians" (Young, 1987; Billock, 1995), and predicts that resulting receptive fields will (1) be large compared with those of type I inputs, (2) have spatially offset center and surround excitatory regions, and (3) show residual cross-talk responses to luminance.

Here we test these predictions by studying the receptive fields of cone-opponent neurons in the next stage of visual processing, primary visual cortex (V1). We used neutral-adapting stimuli to overcome criticisms (Shapley and Hawken, 2002) of previous 
A

\section{lateral geniculate nucleus}

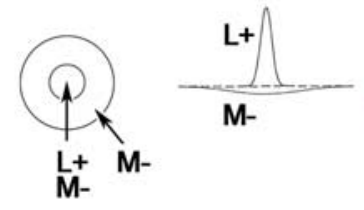

B
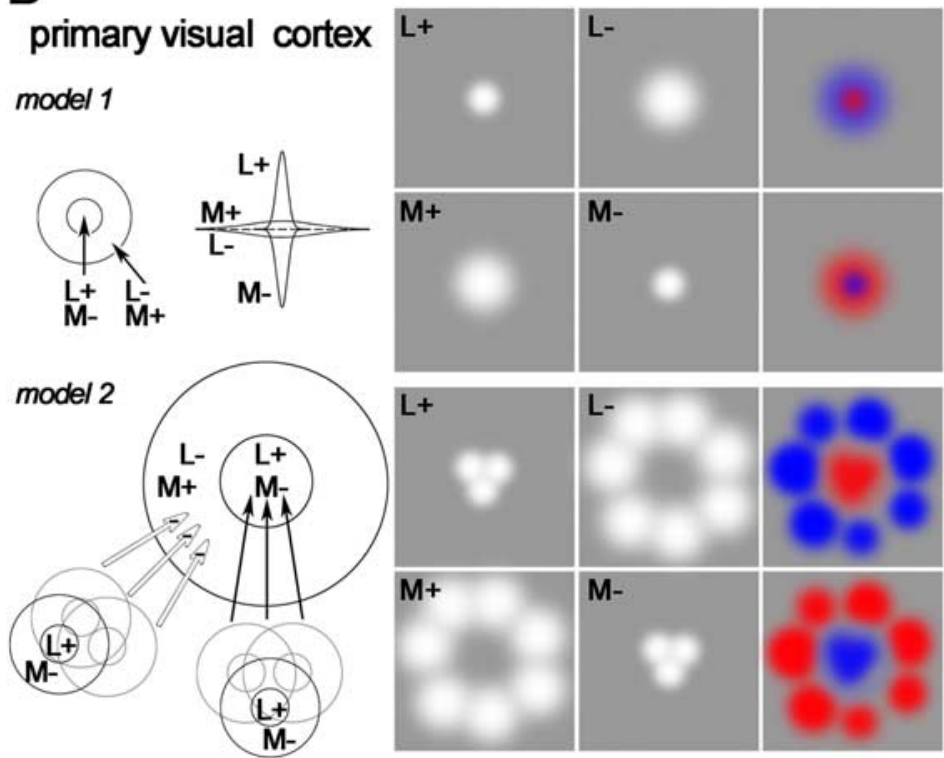

Figure 1. Receptive field of a parvocellular type I cell in the lateral geniculate nucleus $(\boldsymbol{A})$, two theoretical receptive fields capable of spatial color calculations $(\boldsymbol{B})$, and predicted response maps. $\boldsymbol{A}$, Receptive field and profile view as a difference of Gaussians (left diagrams) and responses to cone-isolating stimuli (right). Cone-isolating stimuli can either increase $(+)$ or decrease (-) the activity of a single cone class. This cell shows excitation to $\mathrm{L}+$ and a broader region of excitation to $\mathrm{M}-$ (white regions in the response maps). Note that the optimal stimulus is not a red spot on a green background but rather a bright red spot on a dark red background. The colored squares behind $\mathrm{L}+, \mathrm{L}-, \mathrm{M}+$, and $\mathrm{M}$ - provide a rough idea of what cone-isolating stimuli look like. $\boldsymbol{B}$, Model 1 shows a set of Gaussians that produce spatial and chromatic opponency. The peaks of all predicted response maps are centered at the same location. Model 2 , which also produces chromatic opponency, is built up from many red-0N type I cells: cells feeding the center are wired with excitatory connections and cells feeding the surround with inhibitory connections (adapted from Billock, 1991). The peak response to the $\mathrm{L}-$ stimulus will be offset from the peak response to the $\mathrm{L}+$ stimulus.

cone-isolating methods (Conway, 2001). The spatiotemporal receptive-field maps generated here can be directly compared with LGN cell maps of Reid and Shapley (2002) and support models like that of Billock.

Finally, it is known that light increments are less visible than light decrements (Whittle, 1986; Bowen et al., 1989). By measuring the responses to stimuli that increase the activity of a given cone $(+$ stimuli) separately from the responses to stimuli that decrease the activity of a given cone ( - stimuli), we tested for asymmetries in V1 responses that might account for this phenomenon.

\section{Materials and Methods}

\section{General design}

Experiments were conducted in alert adult male macaque monkeys using chronic recording procedures described previously (Livingstone et al., 1996; Conway and Livingstone, 2003). All experiments were performed according to National Institutes of Health guidelines for the use of animals and with the approval of the Harvard Medical School Standing Committee on the use of animals. Macaques are a useful model for hu- man color vision because psychophysical data from them match those of humans (De Valois et al., 1974; Sandell et al., 1979); the psychophysical results on human color matching are well predicted from the spectral sensitivities of the macaque cones (Baylor et al., 1987). Moreover, using alert animals overcomes the effects of anesthesia, which alter motion tuning (Pack et al., 2001) and may interfere with color processing (Solomon et al., 2004).

Well isolated single units were recorded from V1 using tungsten microelectrodes (Hubel, 1957) (Frederick Haer Company, Bowdoinham, ME). Units were isolated using a dual-window discriminator (BAK Electronics, Germantown, MD) after they were amplified and bandpass filtered $(1-10 \mathrm{kHz})$. Ambiguous single units were discarded if $>2 \%$ total spikes for a given run were in the first millisecond bin of the interspike interval histogram.

Spikes were collected at $1 \mathrm{~ms}$ resolution. Stimuli were presented (in a dark recording chamber) on a 21 inch monitor (Barco Display Systems, Kortrijk, Belgium) with a $60 \mathrm{~Hz}$ refresh rate (non-interlaced). The monitor screen was $57 \mathrm{~cm}$ in front of the animal for some experiments and $39 \mathrm{~cm}$ in others. The animal was given a juice reward for keeping its gaze within $1^{\circ}$ of a fixation spot, and spikes were rejected from analysis if they were collected while the animal's gaze was outside $1^{\circ}$ of the fixation spot. Eye position was monitored using either a search coil in a magnetic field (Judge et al., 1980) or the ISCAN (Burlington, MA) system; the field-coil system was from CNC Engineering (Enfield, CT). Data were not corrected for eye position. Eye monitoring was only done to ensure that the monkeys maintained fixation. Microsaccadic eye movements do not have a significant effect on measured receptive fields in well trained animals, as were used here (Tsao et al., 2003).

From a continuous history of spike timing and stimulus position (at $1 \mathrm{~ms}$ precision), the activity was reverse correlated to produce a spatiotemporal record of the neural response (Jones and Palmer, 1987; Conway, 2001; Conway and Livingstone, 2003; Livingstone and Conway, 2003). The response maps provide a complete description of the first-order receptive fields of the neurons.

This approach is similar to that used by Reid and Shapley (2002) to map LGN neurons with three minor differences. First, the stimuli used here were sparse noise as opposed to checkerboards that modulate each element in the entire stimulation window. Second, the present stimuli were not constrained to be displayed within a grid, allowing higherresolution maps (Martinez et al., 2005). Third, the responses to stimuli that increase the activity of a given cone class ("bright" or + stimuli) were analyzed separately from the responses to stimuli that decrease the activity of a given cone class ("dark" or - stimuli).

\section{Screening for cone-opponent cells}

Quantitative receptive-field analysis was performed only on neurons that gave some indication of cone opponency to an initial screening test. A description of the cone-isolating stimuli $(\mathrm{L}+, \mathrm{L}-, \mathrm{M}+, \mathrm{M}-, \mathrm{S}+, \mathrm{S}-$ ) (Fig. $1 \mathrm{~A}$ ) is given below (see below, Visual stimuli). Neurons were first hand mapped using a computer mouse to adjust the stimulus location on the stimulus monitor while listening to the responses on an audio monitor; hand mapping included small spots of cone-isolating light that were flashed $(\sim 1 \mathrm{~Hz})$ in and around the receptive fields. For screening, a brief 
run of the quantitative mapping stimulus (see below, Visual stimuli) was used to test for opposite patterns (excitation vs suppression) in the difference responses (see Eq. 3 ) to the three cone classes. Data was analyzed on-line; cells showing excitation to one cone type and suppression to another, in any region of their receptive fields, were subsequently mapped with longer stimulus runs. Neurons that were excited or suppressed by both $\mathrm{L}$ and $\mathrm{M}$ but were nonresponsive to $\mathrm{S}$ were classified as luminance selective. The screening method did not require that the neurons show excitatory rebound responses to the cessation of a suppressive stimulus. This is important because color-coding neurons often lack excitatory discharges after cessation of suppressive stimuli (Friedman et al., 2003). Note that the screening methods did not presuppose discrete categories of cone-opponent cells.

\section{Visual stimuli}

Cone-isolating stimuli were used to evaluate the cone inputs. These stimuli were presented under neutral-adapting conditions produced by a neutral gray background. The gray-adapting field maintained a constant level of activation of all three cone classes, allowing a direct comparison of the responses to different cone-isolating stimuli. In addition, because the cone-isolating stimuli had spatial structure (they were small spots), they allowed a direct evaluation of the spatial organization of the cone inputs. Small patches of the background were replaced with a color that altered the activity of a single cone class at a time, a method called silent substitution. A + stimulus increased the activity of the respective cone; a - stimulus decreased it. The six cone-isolating stimuli used were as follows (Commission Internationale de l'Eclairage coordinates: $x, y$, luminance in $\left.\mathrm{cd} / \mathrm{m}^{2}\right): \mathrm{L}+(0.413,0.262,30.7), \mathrm{L}-(0.209,0.277,21.3), \mathrm{M}+$ $(0.223,0.336,28.1), \mathrm{M}-(0.378,0.224,22.5), \mathrm{S}+(0.254,0.155,23.1)$, and $S-(0.376,0.382,25.9)$. Two additional achromatic luminance stimuli were also used in some experiments. These were generated by maximal (white: $70 \mathrm{~cd} / \mathrm{m}^{2}$ ) and minimal (black: $<1 \mathrm{~cd} / \mathrm{m}^{2}$ ) gun activities. The adapting background for all experiments was $(0.318,0.271,25)$; the mean luminance $\left(25 \mathrm{~cd} / \mathrm{m}^{2}\right)$ ensured the stimuli were well within the photopic range. The cone fundamentals of Stockman and Sharpe (2000) were used to estimate cone activity. $\mathrm{L}$ and $\mathrm{M}$ stimuli were calculated to have equal Michelson's contrast, as follows:

$$
\left[(\mathrm{L}+)-\left(\mathrm{L}_{\mathrm{bk}}\right) /(\mathrm{L}+)+\left(\mathrm{L}_{\mathrm{bk}}\right)\right] \times 100 \%,
$$

where $\mathrm{L}+$ is the $\mathrm{L}$ cone activity produced by the $\mathrm{L}+$ stimulus, and $\mathrm{L}_{\mathrm{bk}}$ is the activity of the $\mathrm{L}$ cone produced by the neutral background. The $\mathrm{M}+$ and $\mathrm{L}+$ stimuli had $+17 \%$ contrast; the $\mathrm{M}-$ and $\mathrm{L}-$ stimuli had $-17 \%$ contrast. The $\mathrm{S}+$ and $\mathrm{S}-$ stimuli each had $41 \%$ contrast. This resulted in the following Weber's contrasts: $\left[(\mathrm{L}+)-\left(\mathrm{L}_{\mathrm{bk}}\right) /\left(\mathrm{L}_{\mathrm{bk}}\right)\right]: \mathrm{L}+$ was $0.40 ; \mathrm{L}-$ was $-0.29, \mathrm{M}+$ was $0.40, \mathrm{M}-$ was $-0.29 ; \mathrm{S}+$ was 1.41 , and $\mathrm{S}-$ was -0.60 . According to colorimetric mixing principles, this produces a + and - sum that is slightly brighter than the background, although the stimuli used were constrained so that the overlap was the background gray. Detailed methods for generating cone-isolating stimuli were given previously (Conway, 2001; Reid and Shapley, 2002).

Note that both $\mathrm{L}+$ and $\mathrm{M}-$ look red, but $\mathrm{L}+$ is brighter than the background and $\mathrm{M}-$ is darker (Fig. $1 A$ ). Therefore, + and - also constitute a luminance stimulus; this is a feature of all cone-isolating stimuli. Some studies have attempted to avoid this luminance component by modulating two cone classes at once, for example by combining an L+ and an M- (Derrington et al., 1984; Lennie et al., 1990). We chose not to use such stimuli so that we could directly assay the inputs of the different cone types and of the + and - states of each cone type, separately.

Stimuli were sparse noise. During any given frame, only two small patches of the neutral background were replaced with a cone-isolating color: one of the spots increased the activity of the given cone type ( $\mathrm{a}+$ stimulus) and the other decreased it (a - stimulus). The patches were between 0.25 and $0.75^{\circ}$ square; the patches had no fixed spatial relationship to each other from one frame to the next. The size of the patches was chosen to be the smallest that still reliably elicited responses. Both patches were the same size and were the same size for all cone stimuli, for a given cell.

In any given frame, the two patches could be displayed anywhere relative to each other, at $\sim 0.06^{\circ}$ pixel resolution within a stimulation window between 2.25 and $4.5^{\circ}$ square centered on the receptive field. If the patches overlapped, the overlap region appeared as the adapting gray. Enough stimuli were presented so that all locations within the stimulation window were sampled evenly; on average, five presentations were delivered to each pixel location; stimulus runs were on an average 17.5 min per cone map (range of $2-55 \mathrm{~min}$ ). In most cases, the stimulation window extended well beyond both the center and the surround of the receptive field. The same stimulus run (and spike train) was used to generate the response maps for both spots, which was possible because the presentation position of the two spots was independent (the two spots had no consistent spatial relationship from frame to frame). While generating the response map for one of the spots, the activity produced by the other spot was averaged uniformly throughout the map. This average activity, which is common to both + and - maps, is removed during analysis by considering only the difference in activity between the two maps (see below, Data analysis).

The stimulus durations were either 34,51, or $68 \mathrm{~ms}$ (two, three, or four frames) and are stated in the figure legends. The same stimulus duration was used to generate all maps for a given cell. The spatial maps were unaffected by the choice of stimulus duration. In a few cases, a $17 \mathrm{~ms}$ stimulus duration (one frame) was used to maximize data collection, although such brief flashes did not always reliably elicit spikes.

\section{Chromatic aberration}

As in all studies of color vision, the spatial distribution of shortwavelength light stimuli, including S-cone stimuli, is confounded by chromatic aberration. The effects of chromatic aberration and the preretinal absorption characteristics of the eye are especially significant for neurons recorded at eccentricities $>10^{\circ}$ (Cottaris, 2003). All neurons in the present study were between 2 and $8^{\circ}$, making it unlikely that chromatic aberration had a significant impact.

\section{Data analysis}

Response maps show neural activity, in spikes per second, according to a color scale bar. Reverse correlation typically is reported as a probability of a stimulus preceding a spike, but this can be converted into firing rate according to Bayes' Rule:

$$
P(\text { spike } / \text { stim })=P(\text { stim } / \text { spike }) \times P_{\text {spike }} / P_{\text {stim }},
$$

where $P$ (spike/stim) is the probability of a spike given a stimulus (the firing rate), $P($ stim/spike) is the probability of a stimulus preceding a spike, $P_{\text {spike }}$ is the probability of a spike and $P_{\text {stim }}$ is the probability of a stimulus (the ratio is a constant).

The response maps, which were smoothed with a $0.1^{\circ}$ wide Gaussian filter in both spatial dimensions, are depicted with a $0.75^{\circ}$ overlying grid to assist in comparing the patterns in different maps for a given cell. The locations of the stimuli were not constrained by this grid. Stimuli were positioned with 1 pixel resolution $\left(0.06\right.$ or $0.08^{\circ}$ depending on the distance between monkey and monitor).

The first-order reverse correlation for each stimulus run produced two maps, one for each stimulus: a + map, showing the response to an increase in activity of the given cone class, and a - map, showing the response to a decrease in the activity of that cone class. In these "raw" response maps, black indicates 0 firing, and red indicates maximal firing (see Fig. 2, top, + and - maps).

These response maps can be analyzed separately or they can be subtracted:

$$
\text { difference response }=(\text { response to }+)-(\text { response to }-) \text {. }
$$

This subtraction discounts the baseline firing rate, which is common to both + and - responses for a given cone map. The baseline firing rate is determined by the average activity of the neuron throughout the stimulus run so that, for stimuli that cause considerably more activity, the baseline is higher (e.g., compare the baseline response to S-cone stimuli, to which the neuron was less sensitive, with that to the M- or L-cone stimuli in Fig. 10). Subtraction was used to quantify the data shown in Figures 5, 7, 11, 13, and 16 and supplemental Figure 2 (available at www.jneurosci.org as supplemental material). In the subtracted maps (see Fig. 2, top, difference map), white indicates no difference between 
the + and - maps, black indicates maximal suppression, which could result from any combination of real suppression in the + map and excitation in the - map, and red indicates maximal excitation, which could result from any combination of excitation in the + map and suppression in the - map. SDs were taken as the sum of the SD of the + map and that of the - map, divided by $\sqrt{ } 2$.

To generate fraction-of-background responses (see Figs. 3, 17), we used raw maps, comparing responses of each stimulus $(+$ or - ) with the baseline firing rate, defined as the average firing rate at a reversecorrelation delay between 0 and $10 \mathrm{~ms}$, before the visual latency of the cell was reached:

$$
\text { response }=[(\text { raw response }- \text { background }) / \text { background }] .
$$

To compare ON and OFF responses (see Fig. 4), we subtracted the background response from the responses of the stimuli $(+$ or -$)$ that produced center excitation:

$$
\text { response }=(\text { raw response }- \text { background }) .
$$

Responses were the average throughout the significantly active region (see below, Method 3, area response).

\section{Defining receptive-field center and surround}

The analysis required identification of the center and the surround subregions of the response maps. Several methods were used to define these regions, to facilitate comparison with other studies. Note that the peak response of the "surround" of LGN cells is centered at the same visual field location as the center. Surround signals of LGN cells are distinguished because they cover a wider area and are generally weaker than the centers (Fig. $1 \mathrm{~A}$ ), but it is only by subtracting the surround response from the center response that the stereotypical center-surround LGN receptive field is generated. The receptive-field structure of coneopponent cortical neurons is fundamentally different: as we show, the peak response of the surround is centered at a different receptive-field location. To directly assay this spatial offset, we analyzed the unsubtracted maps. To compare the responses with the LGN responses, which are based on difference maps, we also show an analysis of subtracted maps. There is no consensus on whether analysis should be based on peak responses or average responses throughout the receptive field. We therefore analyzed the data in both ways, yielding four separate analyses determined by the following: (1) the peak (i.e., point) unsubtracted response (Eq. 5); (2) the peak difference response (Eq. 3); (3) the average significant (i.e., area) unsubtracted response; and (4) the average significant difference response. In all major conclusions, the methods produced the same results. A comparison of the results of the different methods is shown in supplemental Figure 2 (available at www.jneurosci.org as supplemental material). The specific method used for each analysis is given in each figure legend.

Quantification and analysis was done using programs written in Matlab (Mathworks, Natick, MA).

\section{Defining center and surround maps}

The first step of all four methods introduced above was to define, for a given cell, one of the maps ( + or - ) of each cone stimulus as the center map (the other is then the surround map). Thus, for a neuron in which all three cone response maps were determined, there were three center maps and three surround maps.

The + or - map containing the earliest excitatory response was defined as the center map. For the cell shown in Figure 2, the L + map and the $\mathrm{M}-$ map would be center maps and the $\mathrm{L}-$ and $\mathrm{M}+$ maps would be surround maps; these responses were categorized as ON-center (excitation to the + stimulus) and OFF-center (excitation to the - stimulus) accordingly. It was necessary to use the earliest excitatory response because some neurons gave temporally biphasic responses: the first phase, suppression, corresponding to the onset of the stimulus; the second phase, excitation, corresponding to the cessation of stimulation (see Figs. 11, 16). Center and surround maps were defined by stimulusonset responses, not rebound responses. The spatial offset of the peak center location within the center maps for a given cell was $<0.2^{\circ}$ and usually $<0.1^{\circ}$.

\section{Determining receptive-field subregions within center and} surround maps

Method 1, peak response. The center location was defined as the absolute peak response within the center map. The center location has spatial coordinates, corresponding to degrees of visual angle, and temporal coordinates, corresponding to the optimal reverse-correlation delay. The peak responses at the center location were determined in the separate + and - maps.

The peak surround also has spatial and temporal coordinates. The spatial coordinates were defined by the peak response in the surround map, within $\pm 10 \mathrm{~ms}$ of the peak center response. The temporal coordinates were defined by the reverse-correlation delay of the peak response at this location, within the surround map, at any reverse-correlation delay. The temporal coordinates of the peak surround response are therefore not restricted to a fixed temporal window. The response at the spatial and temporal coordinates of the surround were then determined in the separate + and - maps.

Note that the temporal window used to define the spatial location of the surround was not long enough in duration to include excitatory rebound responses to the cessation of the stimulus because the stimuli durations were $34 \mathrm{~ms}$ or longer and the temporal window was $10 \mathrm{~ms}$.

When analyzed using this method, a neuron theoretically could produce a response having an identical center and surround location (both spatial and temporal coordinates). This was crucial to be able to evaluate the spatial (see Fig. 9) and temporal (see Fig. 12) offset of center and surround. Figure $7 A$ and supplemental Figure 2 (peak) (available at www.jneurosci.org as supplemental material) show data analyzed using this method.

Method 2, peak difference response. The location of the peak excitatory difference response defined the center location for ON-center maps; the location of the peak suppressive difference response defined the center location for OFF-center maps. The responses were determined at this location in the separate + and - maps.

The surround region was determined in two steps. First, the response at a temporal delay corresponding to the peak center difference response $\pm 10 \mathrm{~ms}$ was identified. The spatial coordinates of the peak excitatory difference response within this temporal window defined the location of the surround for OFF-center maps, and the spatial coordinates of the peak suppressive difference response within this temporal window defined the location of the surround for ON-center maps. The surround was then defined as the maximum difference response at this spatial location at any reverse-correlation delay, for the OFF-center maps, and the minimum difference response at this spatial location at any reversecorrelation delay, for the ON-center maps. Responses at the surround location were then measured in the separate + and - maps.

This method constrains the surround response to be in a spatial location offset from the center location. To be significant, the surround response had to be different from the average difference response by $>2.5$ SDs of the mean difference response. This method is similar to those that use peak responses to cone-isolating gratings in which one phase of the grating is bright and the other dark. See supplemental Figure $2\left(\right.$ peak $\left.^{d}\right)$ (available at www.jneurosci.org as supplemental material).

Method 3, area response. The spatial extent of the receptive-field center was defined as that occupied by a response $>2.5$ SDs above the background for the center maps, at the optimal reverse-correlation delay. To be considered significant, the region had to cover an area of at least $0.2 \times$ $0.2^{\circ}$. The average response of this region was determined in the separate + and - maps.

The temporal coordinates of the surround were the same as for method 1 . The spatial coordinates were determined at this delay, as the response $>2.5$ SDs of the background, at least $0.2 \times 0.2^{\circ}$, in the surround maps. The average responses of this region were determined in the separate + and - maps.

This analysis method (and method 4; see below) is most similar to that of Reid and Shapley (2002), who used area responses. See supplemental Figure 2 (area response) (available at www.jneurosci.org as supplemental material).

Method 4, area difference response. The spatial extent of the receptivefield center was defined as that occupied by a difference response $>2.5$ 
Table 1. Types of $\mathrm{L} / \mathrm{M}$ opponent cells

\begin{tabular}{|c|c|c|c|c|c|c|c|}
\hline \multirow{3}{*}{$\begin{array}{l}\text { Cell type } \\
\text { (center ON) }\end{array}$} & \multirow{3}{*}{$\begin{array}{l}\text { Number of } \\
\text { cells recorded }\end{array}$} & \multicolumn{3}{|c|}{ Number of cells with surrounds } & \multirow{3}{*}{$\begin{array}{l}\text { Double-opponent (cells having a } \\
\text { surround in L or M and S) }\end{array}$} & \multirow{3}{*}{$\begin{array}{l}\text { 3/4-0pponent (cells having a } \\
\text { surround in L/M or S but not both) }\end{array}$} & \multirow{3}{*}{$\begin{array}{l}\text { Single-opponent cells (cells lacking } \\
\text { both L/M and S surrounds) }\end{array}$} \\
\hline & & \multicolumn{3}{|c|}{ Measured cone } & & & \\
\hline & & $\mathrm{L}$ & M & $S$ & & & \\
\hline $\mathrm{L}$ & 41 & 30 of 41 & 30 of 41 & 15 of 23 & 26 of 41 & 8 of 41 & 7 of 41 \\
\hline M & 25 & 19 of 25 & 16 of 25 & 9 of 15 & 15 of 25 & 5 of 25 & 5 of 25 \\
\hline Total & 66 & 49 of 66 & 46 of 66 & 24 of 38 & 41 of 66 & 13 of 66 & 12 of 66 \\
\hline
\end{tabular}

Table 2. Types of $S-(L+M)$ opponent cells

\begin{tabular}{|c|c|c|c|c|c|c|c|}
\hline \multirow{3}{*}{$\begin{array}{l}\text { Cell type } \\
\text { (center ON) }\end{array}$} & \multirow{3}{*}{$\begin{array}{l}\text { Number of } \\
\text { cells recorded }\end{array}$} & \multicolumn{3}{|c|}{ Number of cells with surrounds } & \multirow{3}{*}{$\begin{array}{l}\text { Double-opponent (cells having a } \\
\text { surround in L or M and S) }\end{array}$} & \multirow{3}{*}{$\begin{array}{l}\text { 3/4-Opponent (cells having a } \\
\text { surround in L/M or S but not both) }\end{array}$} & \multirow{3}{*}{$\begin{array}{l}\text { Single-opponent cells (cells lacking } \\
\text { both L/M and S surrounds) }\end{array}$} \\
\hline & & \multicolumn{3}{|c|}{ Measured cone } & & & \\
\hline & & $\mathrm{L}$ & M & $S$ & & & \\
\hline$S$ & 10 & 7 of 10 & 6 of 9 & 2 of 10 & 2 of 10 & 5 of 10 & 3 of 10 \\
\hline$(L+M)$ & 7 & 3 of 6 & 6 of 7 & 6 of 7 & 5 of 7 & 2 of 7 & 0 of 7 \\
\hline Total & 17 & 10 of 16 & 12 of 15 & 8 of 17 & 7 of 17 & 7 of 17 & 3 of 17 \\
\hline
\end{tabular}

SDs above the background difference response for the ON-center maps and $<2.5$ SDs below the background difference response for the OFFcenter maps, at the optimal reverse-correlation delay in the difference map. To be considered significant, the region had to cover an area of at least $0.2 \times 0.2^{\circ}$. The average response of this region was determined in the separate + and - maps.

The temporal coordinates of the surround were the same as for method 2. The spatial coordinates were determined at this delay, as the difference response $<2.5$ SDs of the background difference response, at least $0.2 \times 0.2^{\circ}$ for $\mathrm{ON}$-center maps and as the difference response $>2.5$ SDs of the background difference response, at least $0.2 \times 0.2^{\circ}$, for OFFcenter maps. The average responses of this region were determined in the separate + and - maps. See Figure $7 B$ and supplemental Figure 2 (area response $^{d}$ ) (available at www.jneurosci.org as supplemental material).

Determining the spatial extent of the receptive field and the spatial offset of center and surround (see Figs. 8, 9, 14B)

The total area of the receptive-field center and surround were defined as all parts of the response map that produced responses $>2.5$ SDs of the background, at the optimal reverse-correlation delay of the center and the surround. The extent of the center and surround was then defined as the square root of the total area, to give a sense of the width of the receptive-field subregion. The square root was used for both the center and surround to allow a direct comparison, although the spatial configurations of the center and surround were usually quite different.

The offset $(O)$ of center and surround (for cone maps with significant surrounds), in terms of percentage extent of the receptive-field center, was determined as follows:

$$
O=\left(S / \mathrm{RF}_{\mathrm{c}}\right) \times 100 \%,
$$

where $S$ is the separation (in degrees) between the peak in the center map and the peak in the surround map (see Results, Defining center and surround maps), and $\mathrm{RF}_{\mathrm{c}}$ is the extent of the receptive-field center (in degrees). Offsets were only measured in neurons that had significant responses in both center and surround maps, which was the case for the majority of neurons for the $\mathrm{L}$ and $\mathrm{M}$ maps but less so for the $\mathrm{S}$ map. An offset of $50 \%$ represents half the width of the receptive-field center.

Rebound responses measurements (see Figs. 16B, 17)

Rebound responses to stimulus cessation were quantified for the receptive-field center; results shown in Figure $16 B$ were determined as the peak response after the zero crossing in the spike-triggered average (STA) histograms, using center locations defined by method 2 (see above). These peak difference responses are given as a fraction of the baseline response. In neurons that showed no significant rebound response, the "rebound" was the response of the center at a reversecorrelation delay set by the average time-to-rebound-peak of the population of neurons whose responses were measured using stimuli of the
Table 3. Summary of cone-opponent cells

\begin{tabular}{lllll}
\hline Cell type & $\begin{array}{l}\text { Number of } \\
\text { cells recorded }\end{array}$ & Double-opponent & 3/4-Opponent & $\begin{array}{l}\text { Single-opponent } \\
\text { cells }\end{array}$ \\
\hline Red-green & 66 & 41 & 13 & 12 \\
Blue-yellow & 17 & 7 & 7 & 3 \\
Total & 83 & 48 & 20 & 15 \\
\hline
\end{tabular}

same duration. Rebound responses shown in Figure 17 were determined using Equation 4 above and show the rebound to + stimuli separately from the rebound to - stimuli. Quadrants II and IV contain neurons that showed opposite response patterns (excitation vs suppression) for + stimuli versus - stimuli; quadrant III contains neurons that were suppressed by both + and - stimuli at long delays.

\section{Results}

The spatial and temporal organization of the cone inputs to coneopponent cells in V1 was determined using small patches of coneisolating light presented under neutral-adapting conditions. The cone contrast of the L stimulus was the same as the contrast of the $\mathrm{M}$ stimulus, so the relative strength of $\mathrm{L}$ and $\mathrm{M}$ inputs can be directly determined. The $\mathrm{S}$ contrast was higher.

All neurons had receptive-field eccentricities between 2 and $8^{\circ}$ and were recorded in alert macaques trained to fixate a spot presented in the center of a computer monitor. Each neuron encountered was first hand mapped with patches and bars of coneisolating stimuli, flashed at $\sim 1 \mathrm{~Hz}$, to determine the location of the receptive-field, assay orientation selectivity and screen for cone opponency (see Materials and Methods). This screening procedure did not presuppose discrete categories of coneopponent neurons: to pass the screen, neurons simply needed to show excitation to one or two cone types (and not all three). More than 1152 neurons were screened; 165 cells were studied further. From this, we make a conservative estimate that the number of cone-opponent cells in V1 is $10 \%$. Complete maps of the L- and $\mathrm{M}$-cone inputs were obtained for 83 neurons; L, M, and S maps were obtained for 75 neurons. Sixty-six neurons showed dominant opponency between $\mathrm{L}$ and $\mathrm{M}$ cones (with variable S-cone input), and 17 showed dominant S-cone input, pitted against some combination of $\mathrm{L}+\mathrm{M}$. This population of 83 neurons is the basis for the present study (Tables 1-3). Throughout the paper, we will refer to the $L$ versus $M$ cells (with their variable S-cone input) as red-green and the $S$ versus $L+M$ cells as blue-yellow. This is not intended to indicate that these neurons encode specific 

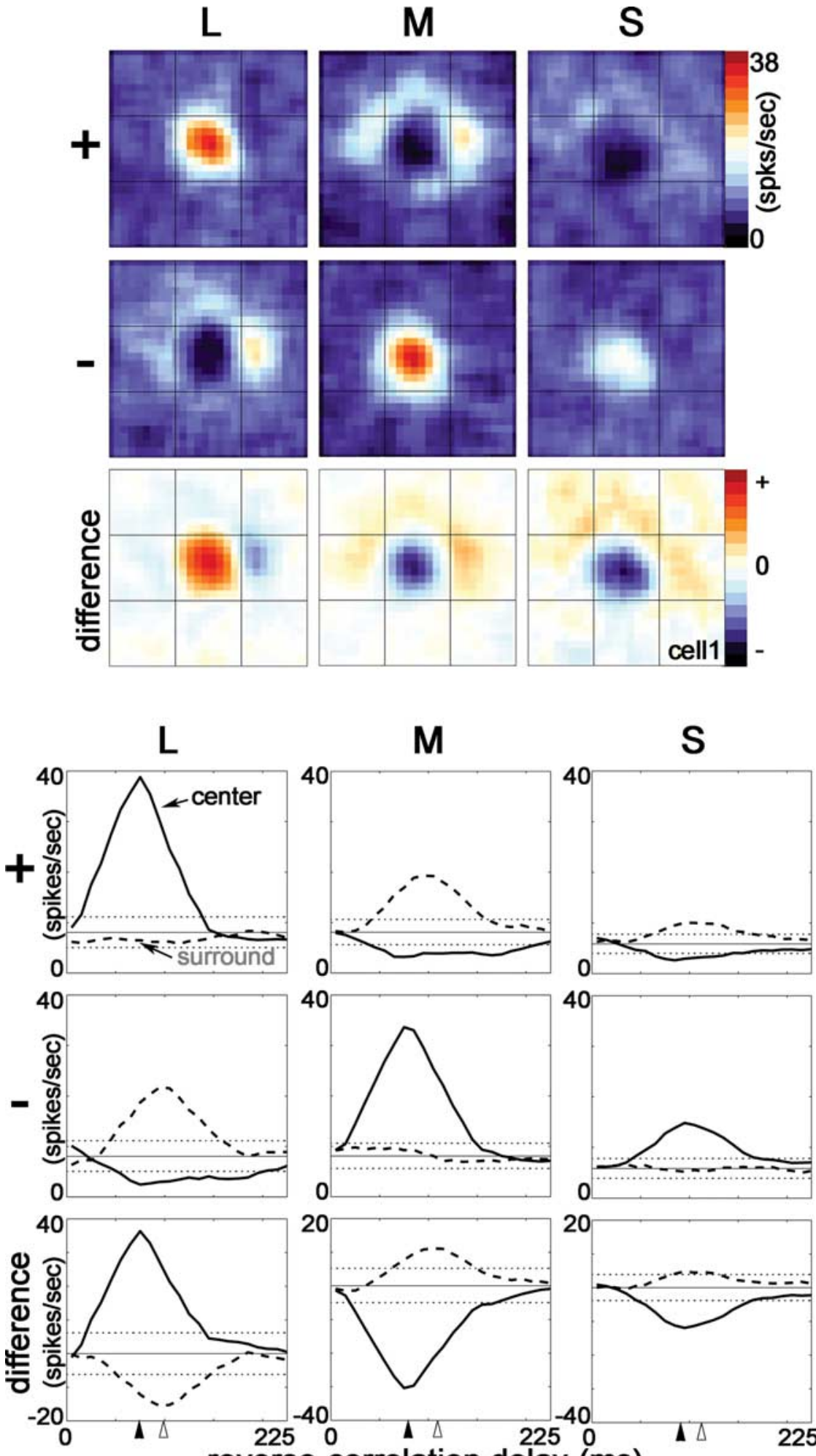

20

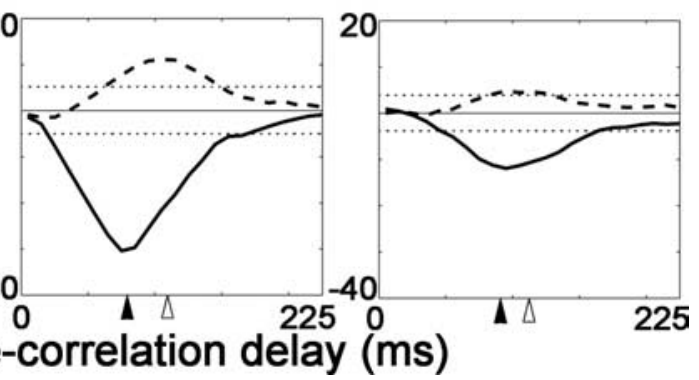

Figure 2. Response maps (top) and the spike-triggered average histograms (bottom) to cone-isolating stimuli for a single cone-opponent neuron in primary visual cortex of an alert macaque. The response maps show the spatial structure of cone inputs to the receptive field at the optimal reverse-correlation delay of the receptive-field center ( $93 \mathrm{~ms}$ ). The difference maps are the response subtracted from the + response and show excitation in red and suppression in blue. The neuron showed both spatial and chromatic opponency, i.e., double-opponency. For this neuron, the peak center is aligned with the center of the response maps. The spike-triggered average histograms show the temporal evolution of the response of the peak center and peak surround locations (method 1 was used to index the center and surround; see Materials and Methods). Two SDs above and below the mean background firing rate are indicated by the horizontal dotted lines. Solid arrowheads show the time-to-peak of the center; open arrowheads show the time-to-peak of the surround. hues but hopefully makes the text easier to read while following traditional naming convention.

\section{Push-pull responses of cone-opponent neurons}

Figure 2 (top) shows the spatial distribution of the responses of a red-ON-center neuron in primary visual cortex to coneisolating stimuli. The temporal pattern, also called the STA histogram or temporal weighting function, is shown at the bottom of Figure 2. The spatial maps show the response at the optimal reverse-correlation delay of the center, $93 \mathrm{~ms}$ (the complete spatiotemporal movie of this neuron is given in supplemental Fig. 1, available at www.jneurosci.org as supplemental material). The maps show non-uniform response distributions, indicating that the receptive field was not homogeneous. To quantify the response, we identified different regions of the receptive field as center and surround. For this neuron, this was easy: the neuron gave a stronger response to one of each $+/-$ pair of stimuli. These maps, $\mathrm{L}+, \mathrm{M}-$, and $\mathrm{S}-$, were therefore defined as center maps, and the location of the peak of the responses within these maps defined the receptive-field center. The location of the center was identical in all center maps. The remaining maps, $\mathrm{L}-$, $\mathrm{M}+$, and $\mathrm{S}+$, were defined as surround maps. The peak response within these maps defined the receptive-field surround. The time course of the response at the center location and surround location was then extracted from the spike train to produce the spike-triggered averages shown in Figure 2 (bottom).

The neuron whose responses are shown in Figure 2 was chromatically opponent. At the location of the receptivefield center, the cell was excited by $\mathrm{L}+$, a stimulus that looks bright red, and suppressed by $\mathrm{M}+$, a stimulus that looks bright green. (Figure $1 A$ gives an approximate idea of what the stimuli colors looked like.) This chromatic opponency was not defined by luminance: the center was also excited by $\mathrm{M}-$, a stimulus that looks dark red, and suppressed by $\mathrm{L}-$, a stimulus that looks dark green. In both cases, the suppression was evident as a reduction in baseline firing, which can be seen in the response maps as a black region at the location of the center in the $\mathrm{M}+$ and $\mathrm{L}-$ maps. This suppression is also clear in the STA histograms: the black traces in the $\mathrm{M}+$ and $\mathrm{L}-$ STAs dip below baseline.

Previous studies have not analyzed separately the responses to the two states of a given cone-isolating stimulus, called 
+ and - , or bright and dark. If the cortex were entirely linear in the way it combined inputs from the two states, it would be superfluous to explicitly distinguish them. However, there is evidence that V1 neurons, especially blue-yellow cells (Horwitz et al., 2005), do not sum signals linearly; moreover, psychophysical research indicates that sensitivity is not equal for light increments and light decrements (see Results, Responses to light increments and decrements).

Distinguishing the responses to the two states allowed us to investigate two issues: first, are the responses of cone-opponent neurons push-pull? Second, do coneopponent neurons show asymmetries between the ON and OFF responses? Pushpull is a term used to describe the functional organization of simple cells in cat primary visual cortex: the lightexcitatory, or ON, subregion is both excited by white and inhibited by dark; the dark-excitatory, or OFF, subregion is both excited by dark and inhibited by light (Ferster, 1988; Hirsch et al., 1998). Each component of a single subregion may be attributed to a distinct retinal process, relayed to the cortex by the LGN. For example, the $\mathrm{ON}$ subregion of a cortical simple cell may receive excitation from $\mathrm{ON}$-center retinal ganglion cells and inhibition from OFF-center retinal ganglion cells. We sought to evaluate whether cone-opponent neurons in primary visual cortex are analogously push-pull: is the receptive-field center of a red-ON cell both excited by $\mathrm{L}+$, an $\mathrm{ON}$ stimulus, and also suppressed by $\mathrm{L}-$, an OFF stimulus? Although extracellular recording does not definitively characterize the mechanism of suppression, intracellular recordings of cat simple cells have shown that extracellular suppression is produced by inhibition (Hirsch et al., 1998).

The neuron shown in Figure 2 was indeed push-pull: L+ caused excitation at the location of the receptive-field center; $\mathrm{L}-$ caused suppression, evident as a reduction of baseline firing rate. This push-pull was also present in the $\mathrm{M}$ and $\mathrm{S}$ maps: at the receptive-field center, the neuron was not only suppressed by $\mathrm{M}+$ and $\mathrm{S}+$ but also excited by $\mathrm{M}-$ and $\mathrm{S}-$.

In Figure 3, we analyze the push-pull organization of all of the color-opponent cells recorded by plotting the degree of excitation versus suppression to each state of each cone class. Suppression is not always apparent with extracellular recording when the baseline firing rate is low, but we found evidence for suppression in the majority of cone-opponent neurons we recorded. Pushpull responses, which were calculated using Equation 4 (see Materials and Methods), are indicated below the $x$-axis or to the left of the $y$-axis (quadrants II and IV). In Figure 3 and throughout this paper, we distinguish different types of neurons, using a naming convention that depends on the identity of the cone whose + stimulus elicited the strongest center excitatory response. The neuron shown in Figure 2 is called an L-ON-center cell and is depicted by a red dot in Figure 3.

The red-green cells in Figure 3 were distributed differently from the blue-yellow cells in the $\mathrm{L}$ and $\mathrm{M}$ plots but not in the $\mathrm{S}$ plot: red-green cells were more frequently located in quadrants II or IV in the L and M plots, indicating push-pull opponency to + and - stimuli; blue-yellow cells were more frequently located in quadrants I or III, indicating a lack of push-pull (see Fig. 15). The distribution was evaluated using a $\chi^{2}$ test. In the L plot, 17 red-

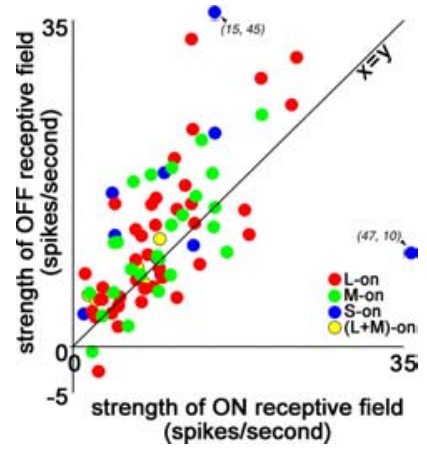

Figure 4. ON and OFF responses in cone-opponent neurons reveal asymmetries in responses to light increments and decrements. The response was determined as the average significant response throughout the center receptive-field subregion (method 3; see Materials and Methods). 0 FF responses were stronger than $0 \mathrm{~N}$ responses (paired $t$ test, $p<0.001$ ). For L-ON cells, the $0 \mathrm{~N}$ response was the response to $\mathrm{L}+$ and the $0 \mathrm{FF}$ response was that to $\mathrm{M}-$; for $\mathrm{M}-\mathrm{ON}$ cells, the $0 \mathrm{~N}$ response was the response to $\mathrm{M}+$ and the $0 \mathrm{FF}$ response was that to $\mathrm{L}-$. For $\mathrm{S}-\mathrm{ON}$ cells, the $0 \mathrm{~N}$ response was that to $\mathrm{S}+$ and the $0 \mathrm{FF}$ response was the average response to $\mathrm{M}-$ and $L-$; for $(L+M)-0 N$ cells, the $0 N$ response was the response to $L$ or $M$ (whichever was stronger), and the OFF response was that to $S-$. The displacement above the $x=y$ diagonal is significant for the red-green cells and for the total population but not for the blue-yellow cells alone.

green cells are located in quadrants I or III and 49 in quadrants II or IV; 12 blue-yellow cells are located in quadrants I and III and 4 in quadrants II or IV. This yields a $\chi^{2}$ value of 13.66 , and a probability of arising by chance $p<0.001$ (supplemental Table $1 A-C$, available at www.jneurosci.org as supplemental material). The $\chi^{2}$ value of the distribution of red-green and blue-yellow cells for the $\mathrm{M}$ plot is $9.4(p<0.01)$. These differences in the distribution of red-green versus blue-yellow cells were not found for responses to the $S$ stimulus, in which both populations of cells showed the same distribution ( $\mathrm{S}$ plot, $\chi^{2}=0.23 ; p<1.0$ ). Neurons that do not show inverted responses (opponency) to + and - stimuli are not push-pull and nonlinear. Therefore, this result shows that on average (1) blue-yellow neurons gave nonlinear responses to $\mathrm{L}$ and $\mathrm{M}$ stimuli and (2) this nonlinearity quantitatively distinguished red-green from blue-yellow cells.

The suppression shown by many neurons to some stimuli resulted in a near complete reduction in background firing rate (Figs. 2, 3), leading one to suspect that the stimulus was capable of more suppression than could by measured extracellularly. To 

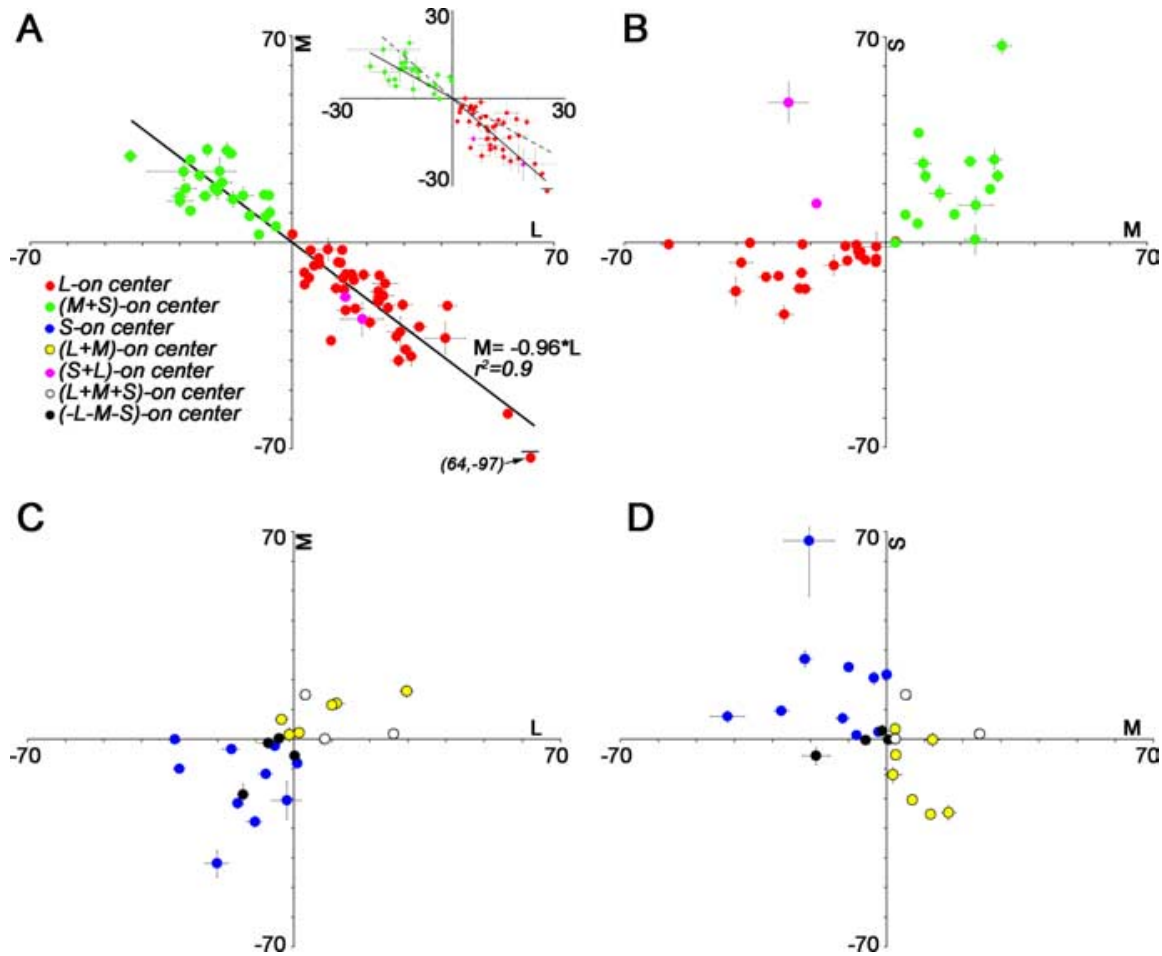

Figure 5. The balance of cone inputs to the receptive-field centers of cone-opponent neurons. Units are spikes per second. Error bars are SDs of the baseline firing rate of each neuron. $A, M$ versus $\mathrm{L}$ input to red-green cells. The regression line combining $\mathrm{L}-\mathrm{ON}$ and $M-0 N$ cells showed balance opponency of $L$ and $M\left(M=-0.96 \times L ; r^{2}=0.9\right.$; measured using the peak difference method, method 2; see Materials and Methods). Area responses (method 4; Materials and Methods) revealed a subtle difference in cone ratios of the two populations, reflected as a kink about the origin when the average $L$ versus $M$ input to $M-0 N$ cells is plotted separately from that to $\mathrm{L}-\mathrm{ON}$ cells (inset; $\mathrm{L}-\mathrm{ON}$ cells, $\mathrm{M}=-1.13 \times \mathrm{L} ; \mathrm{M}-\mathrm{ON}$ cells, $\mathrm{M}=-0.71 \times \mathrm{L}$; regression lines are carried into the adjacent quadrant as dotted lines). This difference reflects the ON/OFF asymmetries shown in Figure 4. B, S versus M input to red-green cells. The majority of red - green neurons were driven by the $S$-cone stimulus, in a manner that pitted $M+S$ against L. $\boldsymbol{C}, \boldsymbol{D}, \mathrm{M}$ versus $\mathrm{L}$ input $(\boldsymbol{C})$ and $S$ versus $M$ input $(\boldsymbol{D})$ to blue-yellow cells and achromatic cells.

overcome this rectification nonlinearity in simple cells, the full extent of the response is often inferred by subtracting the responses to opposite-contrast stimuli (Ferster, 1994). The assumption that the excitatory response to a - stimulus is the same magnitude, but opposite sign, as the suppression to a + stimulus has been shown to be valid for LGN cells in the cat (Martinez et al., 2005). We made this assumption, too, to represent the responses succinctly by difference maps (Fig. 2) (see Materials and Methods, Eq. 3), which allow a direct quantitative calculation of the cone weights. Note that a positive difference can result from any combination of real excitation in the + map and suppression in the - map; similarly, a negative difference can result from any combination of real suppression in the + map and excitation in the - map.

\section{Responses to light increments and decrements}

Light decrements (OFF signals) are both more detectable and more readily discriminated than light increments (Walraven, 1977; Krauskopf, 1980; Whittle, 1986; Bowen et al., 1989; Kremers et al., 1993; Chichilnisky and Wandell, 1996), although the subjective contrast of both, as a function of the background luminance, is essentially symmetric (Burkhardt et al., 1984; Whittle, 1986). The higher salience of decrements is thought to reflect an adjustment by the visual system for the fact that, in the natural world, "the range of increment intensities exceeds the range of decrement intensities (increments may be arbitrarily intense while decrements are bounded by zero)" (Chichilnisky and Wandell, 1996). Asymmetries of ON and OFF responses have been described in parasol retinal ganglion cells (Chichilnisky and Kalmar, 2002) and cone-opponent midget retinal ganglion cells (E. J. Chichilnisky, unpublished observations), but asymmetries in cone-opponent neurons in primary visual cortex have not been explored.

We were able to address this issue because the cone-isolating stimuli generate a luminance signal: the $\mathrm{M}+$ and $\mathrm{L}+$ stimuli are increments $(\mathrm{ON})$ and the $\mathrm{M}-$ and $\mathrm{L}-$ stimuli are decrements (OFF). Luminance values for each of the stimuli are given in Materials and Methods. L-ON and M-ON cells were each excited by one state of the $\mathrm{L}$ stimulus and the opposite state of the M stimulus: each neuron received both $\mathrm{ON}$ excitation and OFF excitation (Fig. 3). For example, the L-ON cell in Figure 2 was excited by both $\mathrm{L}+$ and $\mathrm{M}-$. We investigated whether the $\mathrm{ON}$ and OFF inputs to these neurons were balanced for spatial extent and response magnitude. In general, the $\mathrm{ON}$ receptive fields for $\mathrm{L}$ versus $\mathrm{M}$ cells were slightly larger than the OFF receptive fields $\left(\mathrm{OFF}_{\mathrm{rf} \_ \text {size }}=0.93^{\circ} \times \mathrm{ON}_{\mathrm{rf} \text { size }}\right.$; paired $t$ test, $p<0.003)$, a finding that might not be surprising given that the increments ( + stimuli) had a slightly higher Weber contrast than the decrements (stimuli; see Materials and Methods). Next we tested for differences in the area response magnitude to increments versus decrements (method 4; see Materials and Methods). OFF area response was stronger than $\mathrm{ON}$ area response, indicated by the displacement of the data in Figure 4 (red and green dots $)$ above the $x=y$ diagonal $\left(\mathrm{OFF}_{\text {area response }}=1.2 \times\right.$ $\mathrm{ON}_{\text {area_response }} ; r^{2}=0.54$; paired $t$ test, $\left.p<0.001\right)$. This bias may be even stronger than that shown here because the Weber contrast was lower for OFF stimuli than for ON stimuli.

Blue-yellow neurons were also excited by ON and OFF stimuli, although they did not show consistent push-pull: S-ON cells were excited by $\mathrm{S}+$ and also by $\mathrm{L}-$ or $\mathrm{M}-$ (Fig. 3 ). The blueyellow cells did not, however, show a significant bias in area response magnitude (Fig. 4, blue and yellow dots), which may be attributed to the higher variability of the responses of this population of neurons; additionally, the S-cone stimulus does not have the same luminance relationship as the $\mathrm{M}$ and $\mathrm{L}$ stimuli $(\mathrm{S}-$ is a luminance increment and $\mathrm{S}+$ is a decrement).

How does the magnitude of the asymmetry shown in Figure 4 compare with psychophysical findings? Because the psychophysical effects vary from person to person and depend on the size of the increment/decrement, the stimulus duration, the brightness of the background, and whether the stimuli are colored (Boynton et al., 1964; Chichilnisky and Wandell, 1996), a direct comparison is difficult. However, consider the finding of Bowen et al. (1989) using sawtooth stimuli that there is "a sensitivity advantage of $\sim 0.1 \mathrm{log}$ unit for decremental stimuli at medium to low temporal frequencies $(13 \mathrm{~Hz})$." By interpolating the results of Whittle (1986), who used step stimuli, we infer that a luminance decrement of $-5 \mathrm{~cd} / \mathrm{m}^{2}$ on a background of $25 \mathrm{~cd} / \mathrm{m}^{2}$ (corre- 
sponding to the - stimuli of the $\mathrm{L}$ and $\mathrm{M}$ cones) would need to be an additional $0.6 \mathrm{~cd} / \mathrm{m}^{2}$ dimmer to be discriminated. Conversely, $\mathrm{a}+5 \mathrm{~cd} / \mathrm{m}^{2}$ increment would need to be an additional $4 \mathrm{~cd} / \mathrm{m}^{2}$ to be discriminated. The difference $(4-0.6)$ is $14 \%$ of the background, or $68 \%$ of the step size. By comparison, decrements of the red-green cells elicited an average response $20 \%$ greater than the response to the increments.

\section{Absolute and relative strength of cone inputs to cone-opponent cells}

Figure 5, $A$ and $C$, quantifies the center response to $\mathrm{L}$ and $\mathrm{M}$ stimuli for the population of cone-opponent neurons. As a population, the peak responses (Fig. 5A) and area responses (Fig. 5A, inset) of red-green neurons showed balanced $\mathrm{L}$ and $\mathrm{M}$ input. The area responses suggest that $\mathrm{M}-\mathrm{ON}$ cells and L-ON cells have slightly different ratios of $\mathrm{L}$ versus $\mathrm{M}$ input, reflected as a kink about the origin in the regression lines (Fig. 5A, inset); this difference is attributed to the asymmetry in ON and OFF responses (Fig. 4). By comparison, the whole population of type I cells in the LGN receive balanced, equal and opposite, $\mathrm{L}$ and $\mathrm{M}$ input (Derrington et al., 1984) ${ }^{a}$; however, when considered separately, the two kinds of red LGN cells (L-ON and M-OFF) show slightly different ratios of $\mathrm{L}$ and $\mathrm{M}$ input, as do the two kinds of green LGN cells (M-ON, L-OFF) (Reid and Shapley, 2002).

The majority of red-green neurons we studied also responded to the $\mathrm{S}$-cone stimulus; these responses aligned with responses to the $\mathrm{M}$ stimulus in all but two neurons (Figs. 2, 5B). Because the $\mathrm{M}$ and $\mathrm{S}$ cones are often loosely referred to as green and blue cones and because the combination of green and blue light appears cyan, we suggested calling these cells red-cyan (Conway, 2001). The coupling of $\mathrm{M}$ and $\mathrm{S}$ cones in opposition to L-cone inputs in V1 neurons is supported by other studies (Wachtler et al., 2003) (G. D. Horwitz, E. J. Chichilnisky, and T. D. Albright, unpublished observations).

Unlike the red-green neurons, the blue-yellow neurons showed considerable variation in the magnitude of the input from $\mathrm{L}$ and $\mathrm{M}$ cones (Fig. $5 C, D$ ), with some neurons showing virtually no $\mathrm{M}$ input and others little or no L input. The balance of cone inputs to blue-yellow type II cells in the LGN has not been thoroughly investigated, although the few cases studied show grossly unequal ratios of L and M input (Reid and Shapley, 2002) (but see Chichilnisky and Baylor, 1999).

\section{Spatially opponent receptive-field structure in cone-opponent neurons}

In addition to chromatic opponency, each cone input usually showed spatial opponency, resulting in opponent responses (excitation vs suppression) to stimulation in adjacent regions of visual space. A total of $82 \%$ of cone-opponent neurons showed spatial opponency in at least one of the chromatically opponent systems (either the red or the green of red-green cells; either the blue or the yellow of blue-yellow cells); 58\% showed spatial structure in both opponent systems (Table 3). Spatial opponency was clear in both the raw maps and the difference maps, which have the advantage of subtracting out the common baseline response, leaving a white, zero-difference background (Fig. 2).

${ }^{a}$ In their detailed characterization of the chromatic tuning of neurons in the parvocellular LGN, Wiesel and Hube (1966) distinguished between type III neurons, which do not possess chromatic opponency, and the much more numerous type I neurons, which do. Subsequent work from other groups has suggested that all parvocellular neurons show chromatic opponency. It remains unsettled whether type I and type III neurons represent distinct classes of cells or ends of a continuous spectrum of the same class of cells. We use the term type I to include all LGN parvocellular cells that show cone opponency between $L$ and $M$ cones.
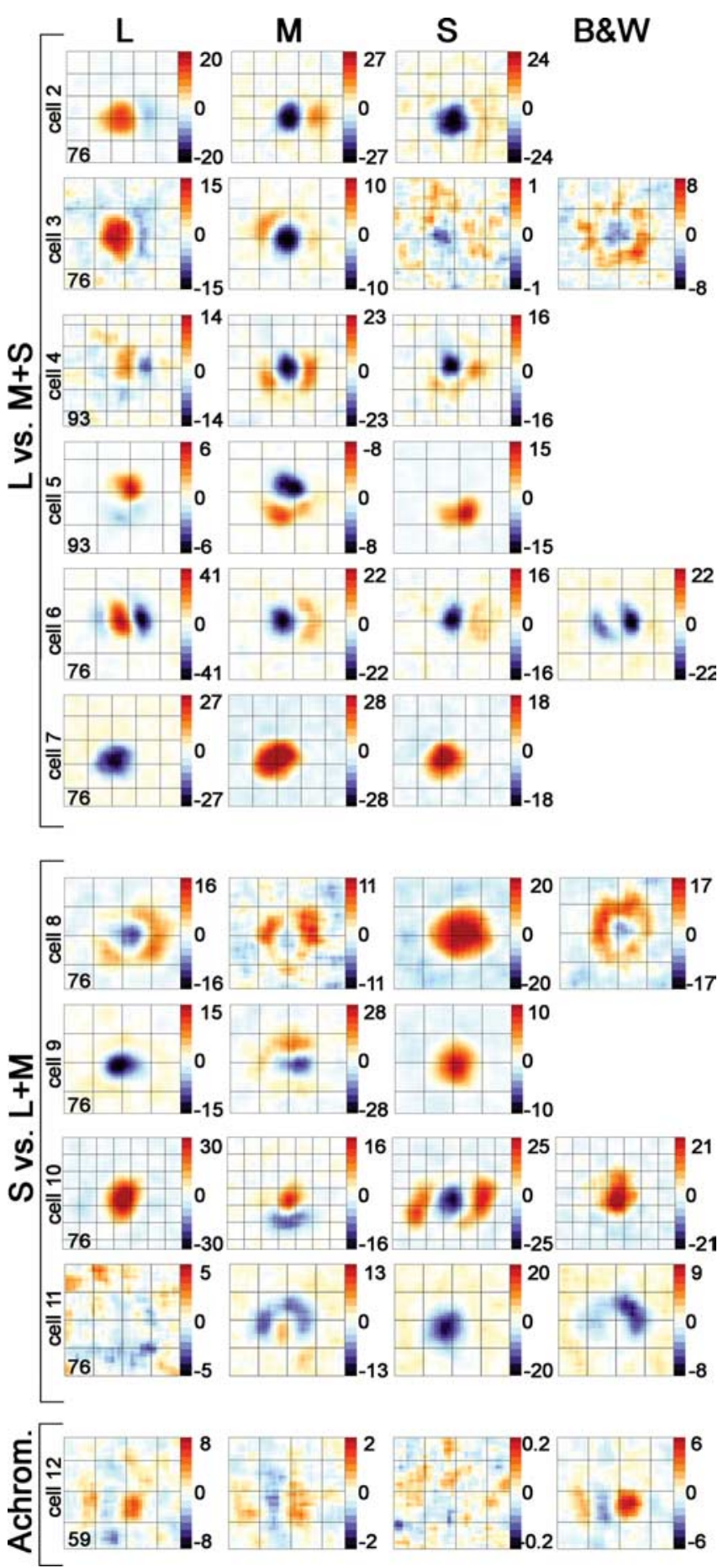

Figure 6. Spatially opponent receptive fields of cone-opponent neurons in V1. Each row represents the cone difference maps for a single cell. Red indicates excitation, and blue indicates suppression. With the exception of the achromatic cell (bottom), all cells showed chromatic opponency. The $L$ versus $M+S$ cells (red-green cells) showed opposite patterns of response (excitation or suppression) between the $L$ and $M$ maps (and often $S$ maps) within a given spatial location. The $S$ versus $L+M$ cells (blue-yellow cells) showed opposite patterns of response within a given spatial location between $S$ and $L$ or $M$ maps. In addition, each single map shows spatial opponency, indicated by areas of excitation and areas of suppression. Spatial scale of the overlying grid is $0.75^{\circ}$. The reverse-correlation delays (in milliseconds) of the response maps are given in the bottom left corner of the $L$ map for each cell. Scale bar is in spikes per second. Complete spatiotemporal maps are shown for cells 2, 3, 4, 8, 10, and 11 in supplemental Figure 7 (available at www.jneurosci.org as supplemental material), supplemental Figure 3 (available at www.jneurosci.org as supplemental material), Figure 10, supplemental Figure 6 (available at www.jneurosci.org as supplemental material), supplemental Figure 5 (available at www. jneurosci.org as supplemental material), and Figure 15 , respectively. 


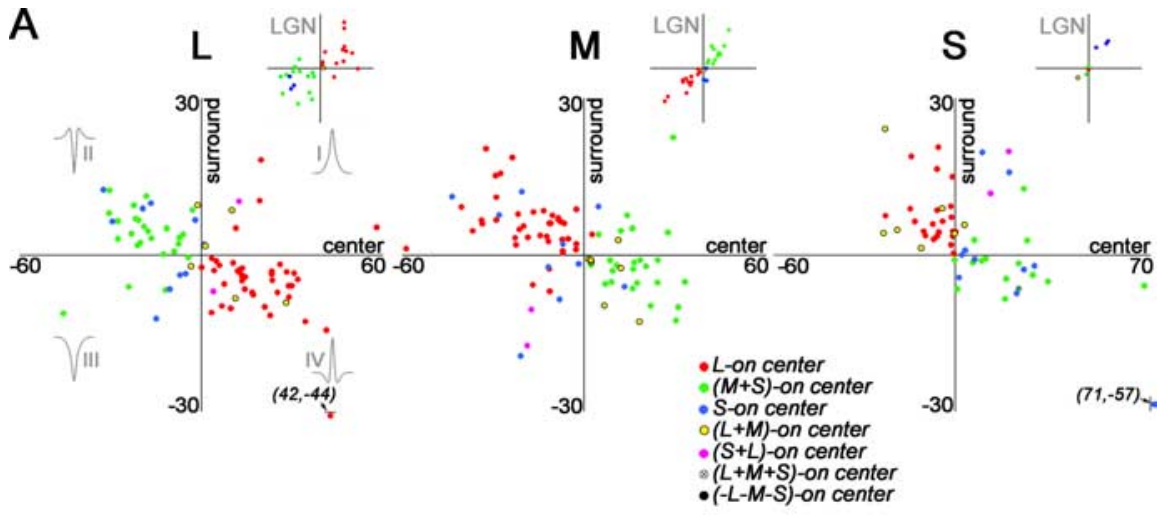

B
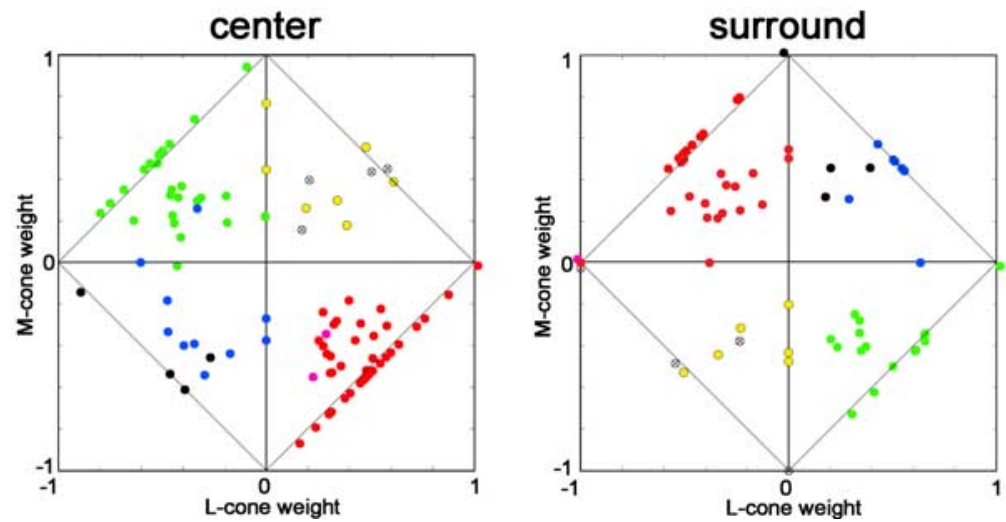

Figure 7. Quantification of center/surround opponency and cone weights. A, Spatial opponency of the L-cone maps (left), M-cone maps (center), and S-cone maps (right). The peak response (method 1; see Materials and Methods) was used to measure the strength of the center versus the strength of the surround. Quadrants II and IV contain neurons that had spatial opponency, indicated by the schematic "Mexican hat" receptive-field profile. Units are spikes per second. $\mathrm{L}_{\text {surround }}=-0.21 \times \mathrm{L}_{\text {center }} r^{2}=$ $0.2 ; \mathrm{M}_{\text {surround }}=-0.22 \times \mathrm{M}_{\text {center }} r^{2}=0.3 ; \mathrm{S}_{\text {surround }}=-0.32 \times 32 \mathrm{~S}_{\text {center }} r^{2}=-0.1$. Insets show LGN responses to similar stimuli; axes limits are 40 spikes/(second $\times$ C), where (is the contrast of the stimulus (data from Reid and Shapley, 2002). Spatial opponency is evident using any method of indexing the center and surround (supplemental Fig. 2, available at www.jneurosci.org as supplemental material). $\boldsymbol{B}$, Cone weights. The sum of the absolute values of the responses (method 4; see Materials and Methods) to each cone stimulus were normalized to a total of 1 . The normalized values of the L-and M-cone inputs are plotted, preserving the sign of the response. The $S$ response is indicated by the distance from the diagonal lines toward the origin. Neurons in which S-cone responses were not measured are depicted outside the diagonal lines; neurons with negligible $S$-cone input lie on the diagonal lines. A red-0N cell having balanced, opponent $L$ and $M$ input, with no S input, would be plotted as $L=0.5, M=$ -0.5 , at the center of the diagonal in quadrant IV.

Against this white background, the L map of the cell in Figure 2 shows excitation in the center and suppression in the surround, depicted as a red region surrounded by a blue crescent. The cell also showed spatial opponency in the other cone system: the $\mathrm{M}$-cone (and S-cone) map shows suppression in the center surrounded by excitation. Like the receptive-field centers, the surrounds of all the cone maps for this cell coincide spatially.

Spatial structure in the difference maps comes about because of the complementary spatial distributions of the responses to the two states of a given cone stimulus. The spatial distribution of one state predicts the spatial distribution of the other: the two responses interdigitate. The interdigitation of + and - responses of a single cone map is analogous to $\mathrm{ON}$ and OFF subregions of simple cells, to light and dark stimuli (Hubel and Wiesel, 1962; Conway and Livingstone, 2003; Tsao et al., 2003), although the structure of the responses in cone-opponent neurons was not luminance dependent. The $\mathrm{M}+$ and $\mathrm{L}+$ stimuli are both brighter than the background, yet elicit inverse patterns of responses in each receptive-field subregion.

The combined spatial and chromatic opponency of the neuron shown in Figure 2 earns it the distinction double-opponent.
Figure 6 shows the difference maps for 11 more neurons, which are grouped into L versus $M+S$ cells (red-green cells) and $S$ versus $\mathrm{L}+\mathrm{M}$ cells (blue-yellow cells). Also shown are the cone maps for a luminance simple cell (Fig. 6, Achrom.). Most of the cone maps show regions of both excitation (red) and suppression (blue), indicating spatial opponency; the spatial opponency between the maps of most of the coneopponent cells are complementary, which was not the case for the achromatic luminance simple cell. For example, the peak response of cell 2 was excited by $\mathrm{L}$ and suppressed by $\mathrm{M}$ and $\mathrm{S}$ (shown in the response maps as a red blob at the center of the L map but a blue blob at this location in the $\mathrm{M}$ and $\mathrm{S}$ maps); the surround (to the right of center) was excited by $\mathrm{M}$ and $\mathrm{S}$ and also suppressed by L. The achromatic cell showed the same spatial pattern of opponency in each map (it received negligible $S$ input, as shown by the noisy S-cone map).

These cone maps reveal several features about the cone-opponent neurons. Few of the double-opponent neurons had completely annular surround responses; rather than being doughnut shaped, as hypothesized previously (Hubel and Wiesel, 1968; Gouras, 1974; Michael, 1978; Livingstone and Hubel, 1984; Billock, 1991), the surrounds were often crescents, or adjacent parallel subfields (Fig. 6, cell 6), much the same shape as the ON and OFF subfields of luminance simple cells. These shapes resemble color basis functions, or filters, generated from Independent Component Analysis of Munsell Color Chips and colored natural scenes (Tailor et al., 2000; Buchsbaum and Bloch, 2002; Doi et al., 2003; Caywood et al., 2004). The asymmetry of the surround also predicts that the neurons will show some orientation preference, and many did as assayed by initial hand mapping (see also Conway, 2001).

For the red-green cells, the surround in one cone map aligned spatially with the surround of the remaining cone maps. For example, the L-OFF surround of cell 2, which sits to the right of the receptive-field center, is in the same spatial location as the $\mathrm{M}-\mathrm{ON}$ surround. This spatial coincidence was not evident in all blue-yellow cells. Cell 10 (Fig. 6) (complete maps in supplemental Fig. 5, available at www.jneurosci.org as supplemental material) shows a crescent-shaped M-OFF surround that sits below the receptive-field center, but the L-OFF and S-ON surrounds straddle the receptive-field center left and right.

Many cells showed reproducible hot spots within the surround (Fig. 6, M-cone map for cell 4). Moreover, the surrounds showed variable spatial extent and strength, relative to the strength of the centers, with some cells showing surrounds of equal size or larger than the center response (Fig. 6, L-cone map, cell 6) and others showing barely significant or insignificant surround responses (for a summary, see Table 3 ). There was no correlation between the magnitude of the response (using any of the methods to define center and surround) and the spatial extent 

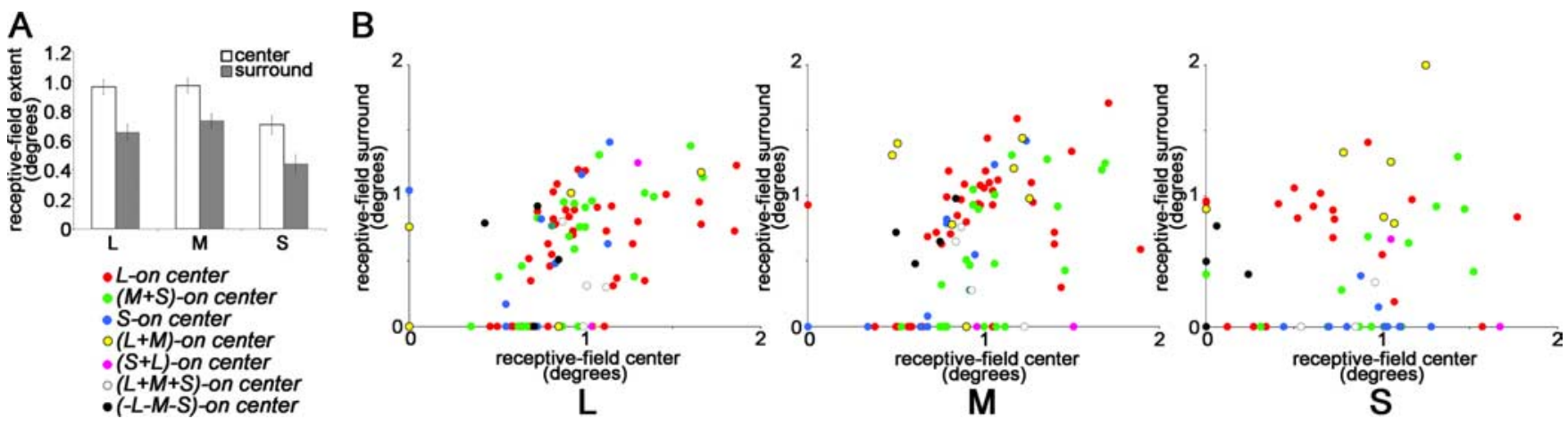

Figure 8. Spatial extent of the receptive-field center and surround. $A$, The average receptive-field surround was more than half the size of the average receptive-field center, for each cone input. SEMs are shown. Measurements are the average response throughout the significant area of activation (method 3; see Materials and Methods), for the whole population of cone-opponent neurons. $B$, Weak correlation between the size of the centers and surrounds. Neurons with insignificant surrounds ( $<2.5$ SDs above the background) are shown along the $x$-axis. Excluding insignificant surrounds, the center/surround correlations are as follows: L plot, $r^{2}=0.35, p=0.005 ; \mathrm{M} \mathrm{plot}, r^{2}=0.26, p=0.04 ; \mathrm{Splot}, r^{2}=0.11, p=0.6$.

of the centers or surrounds (data not shown). Twenty-four percent of cone-opponent neurons had significant surround responses in only one map (Table 3), a pattern of response that has been defined as 3/4-opponent (Livingstone and Hubel, 1984). Three neurons showed a variation of $3 / 4$-opponency in which the surround, but not the center, of one of the cone maps was significant. This is seen in cell 5 (Fig. 6), which showed no significant $\mathrm{S}$ - response but a strong $\mathrm{S}+$ response located exclusively in the surround region defined by the $\mathrm{L}$ and $\mathrm{M}$ maps. These patterns suggest that double-opponent cells are wired by sampling separately the ON and OFF signals from each of the cone types.

In Figure 7, we plot the magnitude of the peak center response against the peak surround response, separately for each cone type. The peak responses of the surrounds were $\sim$ one-fifth as strong as the centers, for each of the cone maps (Fig. 7A), but this analysis gives an underestimate of the strength of the surrounds of spatial-opponent cells because cone-opponent neurons, having insignificant surrounds and which form a discrete population of neurons (see Results, Cone-opponent neurons without spatial opponency), were included. Excluding cells with insignificant surrounds gives surround estimates ranging from approximately one-third as strong as the centers (if method 2, peak difference responses, is used to define center and surround) to approximately two-thirds as strong as the centers (if method 4, area difference responses, is used to define center and surround). A comparison of the results of the different methods is shown in supplemental Figure 2 (available at www.jneurosci.org as supplemental material), in which cells with insignificant surrounds are plotted along the $x$-axes for methods 2 and 4 .

Regardless of the method of analysis, the center versus surround responses of all cone-opponent cells are distributed predominantly in quadrants II and IV for all cone maps, indicating that cone-opponent neurons on average show spatial opponency (Fig. 7A) (supplemental Fig. 2, available at www.jneurosci.org as supplemental material). All methods of analysis also show that the centers and surrounds have opposite chromatic tuning: the L-ON cells are almost exclusively distributed in quadrant IV in the $\mathrm{L}$ cone map and almost exclusively in quadrant II in the M cone map; the M-ON cells show the reverse pattern. Spatial chromatic opponency is underscored in cone-weight plots (Fig. 7B): in the center plot, red-ON cells fall in quadrant II and green-ON cells in quadrant IV, but in the surround plot, red-ON cells fall in quadrant IV and green-ON cells in quadrant II. Blue-ON and yellow-ON cells also swap quadrants. Cone-weight plots also support the conclusion that the red-green neurons receive ap- proximately balanced $\mathrm{L}$ and $\mathrm{M}$ input: both center and surround responses cluster around the midpoints on the diagonals (Fig. $7 B$ ) (see also Fig. 5A). This clustering is similar to that of type I cells plotted in cone-weight space (Derrington et al., 1984). Blueyellow neurons, conversely, did not on average receive equal input from $\mathrm{L}$ and $\mathrm{M}$ cones or show a consistent ratio of $\mathrm{L}$ and $\mathrm{M}$ input, as indicated by the scatter of blue and yellow dots in quadrants I and III (Fig. 7B) (see also Fig. 5C,D). That the cone weights for red-green and blue-yellow cells are nonoverlapping is not an artifact of the selection criteria because neurons were not selected for the type of opponency or for the cone weights they receive.

The spatial organization of the responses of V1 coneopponent neurons can be directly compared with the responses of LGN type I cells. Type I cells fall almost exclusively in quadrants I and III (Fig. 7A, insets) (data from Reid and Shapley, 2002); in contrast, cortical cone-opponent cells fall almost exclusively in quadrants II and IV. This shows that the striate cortex makes a spatial transformation of the cone signals, which produces neurons capable of spatial color comparisons.

Although weaker in magnitude than the centers, the surrounds occupied a relatively large region of visual space ( $\mathrm{L}$ and $\mathrm{M}$ inputs, average of $0.7^{\circ}$ wide), over half the extent of the receptivefield center ( $\mathrm{L}$ and $\mathrm{M}$ average of $\sim 1^{\circ}$ wide) (Fig. $8 \mathrm{~A}$ ). Center and surround sizes were determined by the entire significantly activated region of the response maps. It may be surprising that the surround is actually smaller than the center (compare the sizes of the red and blue blobs in each panel of Fig. 6), unlike LGN neurons in which the surround is usually larger than the center. This is partly attributed to a difference in definition of surround required by cortical neurons (see Materials and Methods, Defining receptive-field center and surround). Moreover, some cortical cone-opponent neurons lack a surround (see Results, Coneopponent neurons without spatial opponency) yet were included in the analysis of Figure $8 \mathrm{~A}$; even excluding these cells, however, the surrounds were still smaller than the centers (Fig. $8 B$ ). There was a weak correlation between the spatial extent of the receptivefield center and the spatial extent of the surround for the $\mathrm{L}$ and $\mathrm{M}$ plots but not the $\mathrm{S}$ plot (L plot, $r^{2}=0.35, p=0.005$; M plot, $r^{2}=$ $0.26, p=0.04$; S plot, $r^{2}=0.11, p=0.6$ ); there was no correlation between the magnitude of the response and the spatial extent of the receptive field for either center or surround (analysis not shown). Despite the smaller surround-to-center size ratio of cortical cells compared with LGN cells, both the centers and surrounds of cortical cells were still larger than centers and sur- 
rounds of LGN cells, whose average receptive-field width at comparable eccentricity is $0.24-0.5^{\circ}$ (Reid and Shapley, 2002).

These results show that, under neutral-adapting conditions, many cone-opponent cells in V1 are double-opponent. This confirms the conclusions using high-color backgrounds (Conway, 2001). High-color backgrounds may provide more reliable estimates of the cone inputs because "transient chromatic adaptation produced by an abrupt change of background color permits an easier and closer approach to cone isolation than does steadystate adaptation" (Stockman et al., 1993). In any event, the receptive-field structure of single double-opponent cells remains relatively stable using both methods (Conway, 2006) and predicts that the neurons will respond optimally to adjacent patches of oppositely colored light (e.g., red next to green). This has been tested, under neutral-adapting conditions, using adjacent patches of $\mathrm{L}+, \mathrm{M}+$, and $\mathrm{S}+$. Such cone-interaction maps have shown that these neurons are capable of performing spatial color calculations (Conway, 2001; Conway et al., 2002).

\section{Spatial offset of receptive-field centers and surrounds}

The models illustrated in Figure $1 B$ make several predictions about the surround, which we tested. Model 1 predicts that the centers and surrounds should have the same peak location, like type I cells. Model 2 predicts that the peak location of the surround response will be offset relative to the center. We plotted the spatial offset of the peak surround response and the peak center response, as a fraction of the spatial extent (receptive-field width) of the center (Fig. 9), using the unsubtracted maps to index the location of the centers and surrounds (Eq. 6; see Materials and Methods). This method is similar to the overlap index used to measure the offset of $\mathrm{ON}$ and OFF subregions in cat simple cells (Schiller et al., 1976; Martinez et al., 2005). The surrounds of cone-opponent cells were significantly offset from the centers. For the red-green cells (Fig. 9A), the peak of the surround in the L maps was offset from the peak center by a distance of $69 \%$ center size, over half the width of the center; the peak surround in the $M$ maps was offset by a similar amount ( $61 \%$ center size). This offset is equivalent to $0.63^{\circ}$ of visual angle (the average receptive-field center was $\sim 1^{\circ}$ ) (Fig. $8 A$ ). The peak surround of the $\mathrm{S}$ maps was offset by a larger amount, $84 \%$ center size, although surround maps were less often significant for the $\mathrm{S}$ cone. L surrounds were significant in $85 \%$ of cells, $M$ in $82 \%$, and $S$ in $58 \%$. (Note the lower maximum counts on the $\mathrm{S}$ histogram compared with the $\mathrm{L}$ and $\mathrm{M}$ histograms in Figure $9 A$; cells with insignificant surrounds are indicated along the $x$-axis in Figure $8 B$.)

The larger offset of center and surround in the S map may reflect the larger size of the presumptive blue-yellow inputs from the retina and LGN compared with the size of red-green type I cells (Wiesel and Hubel, 1966; De Monasterio and Gouras, 1975; Chichilnisky and Baylor, 1999). The surrounds of the blue-yellow cells (Fig. 9B) were also offset, although they showed more variability, and only 2 of the $10 \mathrm{~S}-\mathrm{ON}$ (blue) cells showed significant $\mathrm{S}$ surrounds (Fig. $8 \mathrm{~B}$, Table 2).

The significant offset of the surrounds supports models like that of Billock (1991), illustrated in Figure $1 B$ (model 2), in which the center and surround of a single double-opponent cell are fed by a different pools of type I cells, each pool representing distinct but adjacent patches of retina.

\section{Time course of the response of cone-opponent neurons}

The peak excitation of the $(\mathrm{L}-)$ surround of the neuron shown in Figure 2 was delayed relative to the center, which can be seen in the STA histograms (Fig. 2, center time-to-peak, filled arrow-
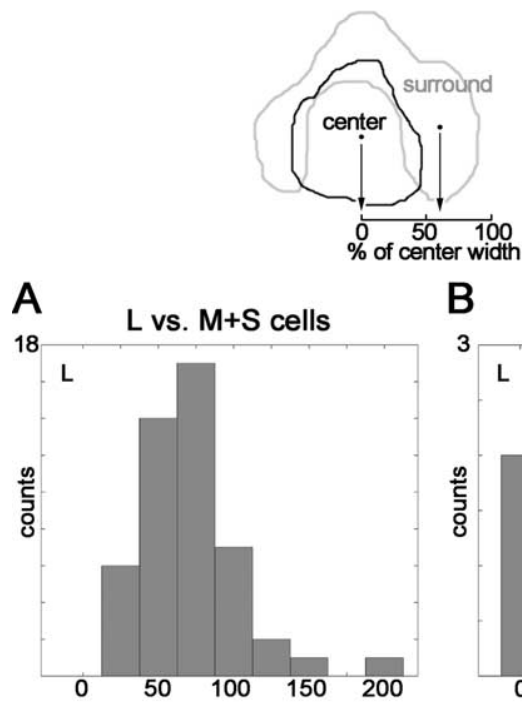

B S vs. L+M cells
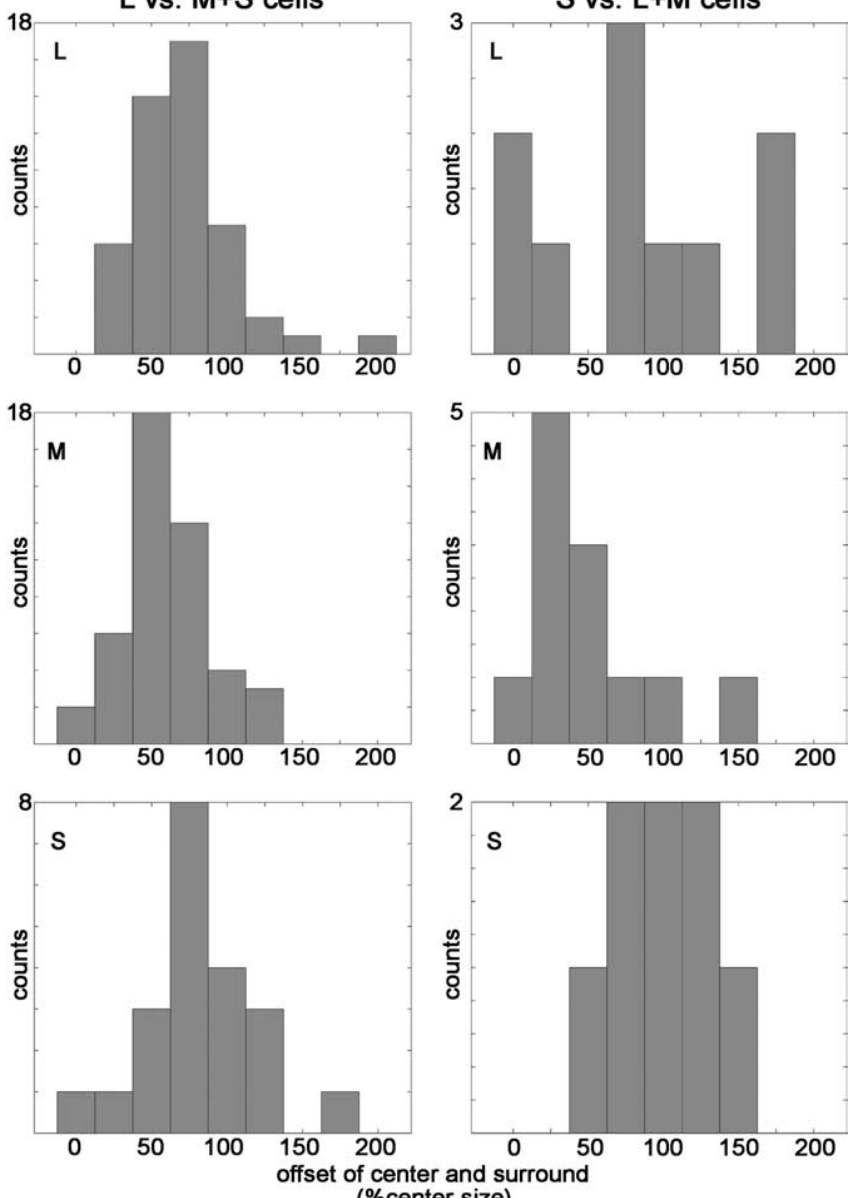

(\%center size)

Figure 9. Offsets of the peak activation of the receptive-field centers and surrounds. Diagram at top shows a contour around the significant regions of activation of the cell shown in Figure 2; peak responses within each subregion are indicated by the dots. An offset of $100 \%$ represents one width of the receptive-field center. One green- $0 \mathrm{~N}$ cell and three blue-0N cells had insignificant centers but significant surrounds in at least one of their maps (e.g., cell 5, Fig. 6,S-cone map); these were not included in this analysis. $A$, Center-surround offset of red-green cells. L map, Average \pm SE, $69 \pm 4 \%$; M map, average \pm SE, $61 \pm 4 \%$ (not significantly different from $L$ maps, $p=0.23, t$ test); $S$ map, average $\pm S E, 84 \pm 8 \%$ (different from distribution of $\mathrm{M}$ at $p=0.06, t$ test). $\boldsymbol{B}$, (enter-surround offset of blue-yellow cells. L map, Average \pm SE, $88 \pm 19 \%$; M map, average \pm SE, $50 \pm 39 \% ;$ S map, average \pm SE, $96 \pm 34 \%$.

heads; surround time-to-peak, open arrowheads). This delay is also apparent in the complete spatiotemporal movie of the response, shown in supplemental Figure 1 (available at www. jneurosci.org as supplemental material) for the same neuron and for a second cell in Figure 10. Each frame of each horizontal strip shown in Figure 10 is analogous to a film still, so that an entire strip represents the evolution of the response over time: the initial response is shown by the leftmost frame and represents the average response during the reverse-correlation delay from 0 to 17 $\mathrm{ms}$. The activity at this reverse-correlation delay represents the baseline response because it is shorter than the visual latency of 

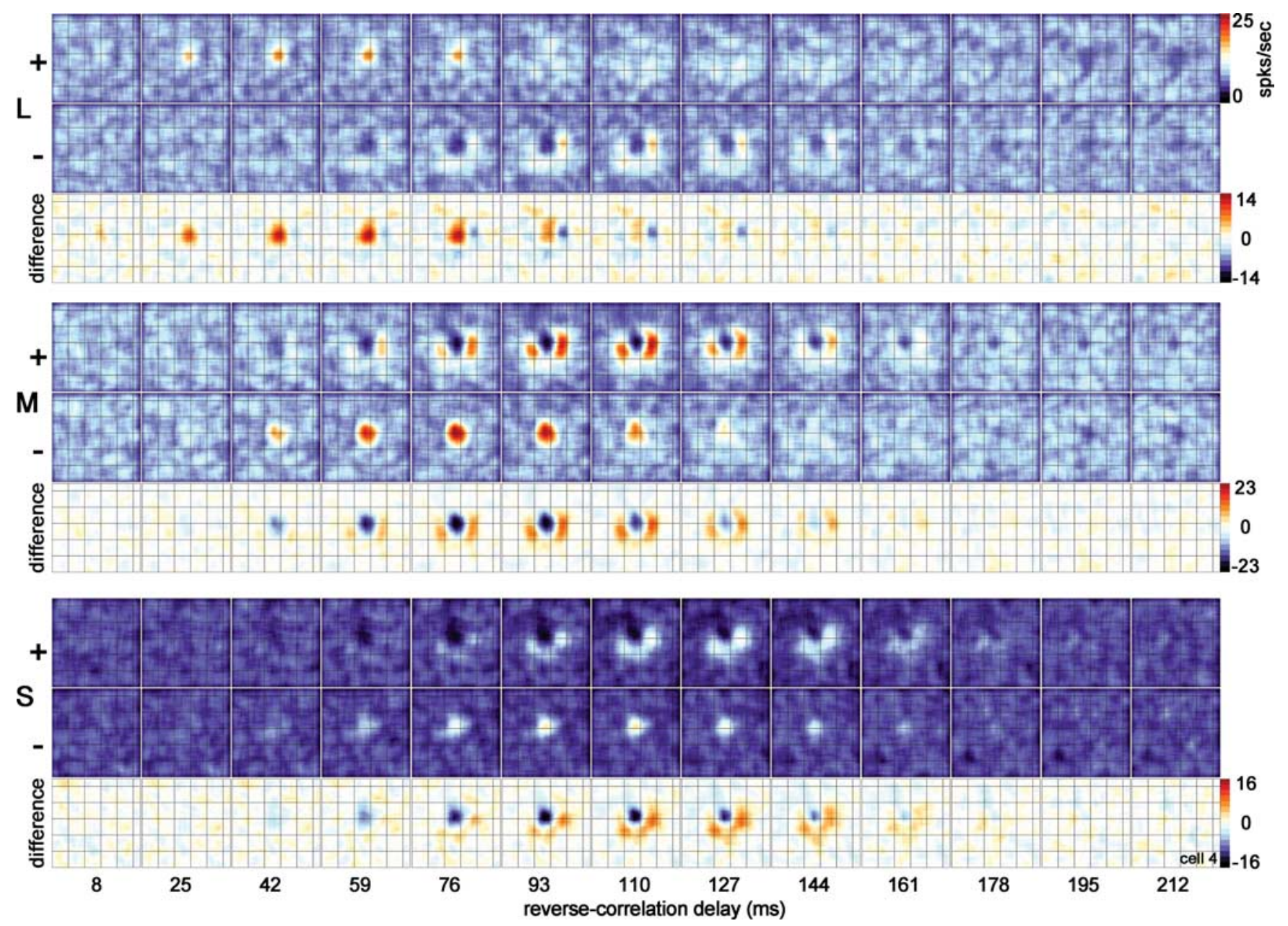

Figure 10. Spatiotemporal response of the cone inputs to a single cone-opponent neuron. The location of the overlying grid $\left(0.75^{\circ}\right.$ gridline spacing) is useful in comparing the location of the responses in different maps. The two states of the stimulus consisted of a bright state $(+)$, which increased the activity of the given cone class, and a dark state $(-)$, which decreased the response of the given cone class. Responses in the + and - maps are indicated by a color scale bar, in spikes per second. Black shows zero firing rate. Responses in the difference maps, constructed by subtracting the - map from the + map, are also indicated by a color scale bar (spikes per second): white shows zero difference, red shows excitation, and black shows suppression. Each single map is the average response over a $17 \mathrm{~ms}$ time window; each horizontal strip shows the evolution of the response over 13 windows (total of $221 \mathrm{~ms}$ ). Maps at the earliest reverse-correlation delay ( $8 \mathrm{~ms}$ ) show no structure; these maps show the average response of the neuron before the visual latency is reached and are a useful measure of the baseline firing rate of the cell under each stimulus condition. Responses to the two states of each stimulus were collected in a single stimulus run. The stimulus size was $0.64^{\circ}$ square, and the stimulus duration was $68 \mathrm{~ms}$.

cortical cells. The center response of this neuron peaks at $\sim 59 \mathrm{~ms}$ (fourth frame from the left). The excitation in the surround peaks later, at $\sim 110 \mathrm{~ms}$ (evident in both the $\mathrm{M}+$ and $\mathrm{L}-$ surround maps).

The spike-triggered average histograms of all cone-opponent cells are shown in Figure 11. The STA histograms illustrate the slower time course of the surround, and they underscore the fact that the surrounds have a chromatic signature that is opposite to that of the centers. The STA histograms were derived using the area difference response method to index the center and surround (method 4; see Materials and Methods); this requires the center and surround regions to be significantly above background and to be spatially offset. Insignificant surrounds are not shown. The number of neurons with significant surrounds is given in Tables $1-3$.

The surrounds of the whole population of double-opponent and $3 / 4$-opponent neurons were delayed by $\sim 11 \mathrm{~ms}(t$ test, $p<$ 0.003 ) (Fig. 12C), although this delay was only significant for the red-green cells ( $t$ test, $p<0.0002$ ) (Fig. 12A; Table 4 ). The discrepancy between the red-green and blue-yellow cells reflects a difference in the timing of $\mathrm{L}$ and $\mathrm{M}$ inputs to blue-yellow cells: the center $\mathrm{L}$ and $\mathrm{M}$ response of the blue-yellow cells was delayed relative to the center response of the red-green cells, by $\sim 8 \mathrm{~ms}(t$ test, $p<0.03$ ) (Table 4); in contrast, the surround had the same time course in both populations. Moreover, there was a tendency for the $\mathrm{S}$-cone responses to be delayed by $\sim 10 \mathrm{~ms}$ relative to the $\mathrm{L}$ and $\mathrm{M}$ responses in the red-green cells but not in the blue-yellow cells (Table 4). The delayed S signal of the surrounds of the redgreen cells resulted in a surround $S$ response that peaked some 20 ms later than the center $\mathrm{L} / \mathrm{M}$ response. These results show that the cone inputs to red-green and blue-yellow cells have different temporal dynamics.

A temporal delay between center and surround is supported by Horwitz, Chichilnisky, and Albright (unpublished observations). The delay of the S-cone signal confirms the results of Cottaris and De Valois (1998) and provides a mechanism for the slightly longer reaction times to stimuli operating through the S-opponent versus L/M-opponent subsystems (Smithson and Mollon, 2004); moreover, the different timing of center and surround, coupled with the chromatically opponent rebound re- 

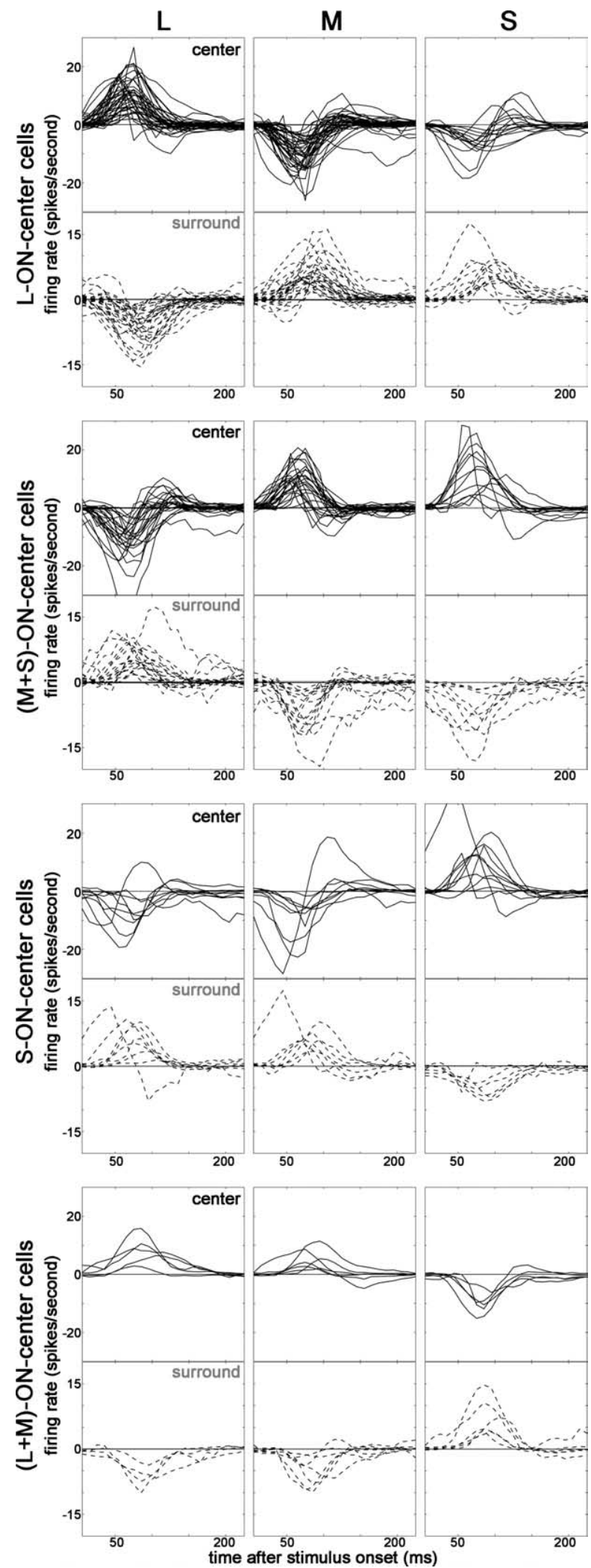

Figure 11. STAs to cone-isolating stimuli of cone-opponent neurons in V1. Bold lines show center responses; dashed lines show surround responses. The STAs show the time course of the difference response (+ response minus - response; see bottom row of STAs in Fig. 2). Each population of neurons shows cone-opponency indicated by the opposite orientation of the response signature between pairs of cone stimuli. For example, the centers of $\mathrm{L}-\mathrm{ON}$ cells show excitation to $L$ and suppression to $M$ and $S$ (top row of histograms). The surround responses show an opposite STA signature to that of the center, indicating spatial opponency. Responses were determined using method 4 (see Materials and Methods). sponses (see below), likely accounts for the shifting color preferences over time of some neurons when they are tested with fullfield stimuli (Cottaris and De Valois, 1998). Finally, the timing differences of center and surround may help explain why doubleopponent neurons have been so resistant to study with drifting sine-wave gratings.

\section{Achromatic responses of cone-opponent neurons}

Responses to achromatic stimuli were measured in 23 coneopponent cells. Many (17 of 23) gave significant responses to white and black stimuli (Fig. 6) (supplemental Figs. 1, 3-6, available at www.jneurosci.org as supplemental material), quantified in Figure 13. The achromatic responses were often not balanced between white and black, and often the achromatic response was stronger than any cone-isolating response despite chromatic opponency (Fig. 13) (supplemental Fig. 3, available at www.jneurosci.org as supplemental material). The response of the cell shown in supplemental Figure 3 (available at www.jneurosci.org as supplemental material) to white had the same structure as the response to black and was almost cancelled in the difference maps. Many neurons, regardless of their dominant center cone, responded better to the black stimulus than to the white stimulus, indicated in Figure 13 as a bias in the responses below the $x$-axis. This may go further in accounting for the lower detection and discrimination thresholds for decrements (see Results, Responses to light increments and decrements).

Many studies have considered a lack of response to white as a key definition of color tuning, so we were surprised to find that cone-opponent neurons responded to achromatic stimuli. Achromatic responses of color-sensitive neurons have been found by others (Conway, 2001; Johnson et al., 2004; Horwitz et al., 2005). Johnson et al. (2001) have used the ratio of the response to equiluminant color and luminance as a means of categorizing neurons. However, given the variable responses of cone-opponent cells to luminance, cone-opponent neurons will be found in each of the categories defined by a color-luminance index, making this categorization method unreliable if cone opponency is the gold standard for defining a contribution to color vision in the early visual system.

One of the predictions of the model of Billock (1991) is that double-opponent neurons will show some cross-talk response to luminance. This prediction arises because of the spatial luminance opponency of the LGN inputs (Fig. $1 A$ ), which are the basis for the model. If many type 1 cells representing overlapping regions of visual space are pooled together, the luminance signal will cancel except at the outer margins of the pool of receptive fields. If Billock's model is correct and distinct pools of type I cells are used to construct the center and the surround, then one might expect the luminance signal in double-opponent cells to be located at the interfaces between the center and the surround. We found evidence for this in seven neurons that showed strong luminance responses (supplemental Fig. 1, available at www. jneurosci.org as supplemental material), although a larger sample will be necessary to confirm this observation.

\section{Cone-opponent neurons without spatial opponency}

Eighteen percent (15 of 83) (Table 3) of cone-opponent neurons did not show spatial opponency (Fig. 14) (supplemental Fig. 4, available at www.jneurosci.org as supplemental material). Supplemental Figure 4 (available at www.jneurosci.org as supplemental material) shows the responses of a neuron that was strongly excited by $\mathrm{L}+$ and $\mathrm{M}-$ stimuli, peaking at $76 \mathrm{~ms}$. The response to the $\mathrm{L}$ stimulus was weaker than the response to the $\mathrm{M}$ 
stimulus, and the cell did not respond well to the $S$ stimulus. Although the cell showed little or no excitatory modulation to $\mathrm{L}-$ and $\mathrm{M}+$, it did respond to these stimuli: it showed a reduction in baseline firing rate at the same time and location as the peak $\mathrm{L}+/ \mathrm{M}-$ excitatory response, suggesting push-pull chromatic opponency (see Results, Responses to light increments and decrements). This singleopponent neuron gave a stronger and faster response to achromatic stimuli than to cone-isolating stimuli. In addition, the achromatic response showed a rebound response, whereas the cone-isolating response did not. Of the 66 red-green neurons we studied, 12 were single opponent (Table 1).

Single-opponent neurons had smaller receptive-field centers than doubleopponent and 3/4-opponent cells. We compared the size of the receptive fields of the single-opponent neurons with those of the double-opponent cells, combining the $3 / 4$-opponent and the double-opponent cells (Fig. 14) (there was no significant difference in receptive-field-center size between double-opponent and 3/4-opponent cells; analysis not shown). The doubleopponent and 3/4-opponent neurons had receptive-field centers that were on average $1.0^{\circ}$ wide $\left(\mathrm{SD}\right.$ of $0.3^{\circ}$ ), whereas the singleopponent neurons were $0.6^{\circ}$ wide $\left(\mathrm{SD}\right.$ of $\left.0.1^{\circ}\right)$, forming two distributions $(t$ test, $p<0.006)$. All neurons were recorded at the same eccentricity, between 2 and $8^{\circ}$.

Anecdotes of chromatically opponent neurons lacking spatial structure suggest that these cells reside in layer $4 \mathrm{C} \beta$ or $4 \mathrm{~A}$ (Livingstone and Hubel, 1984; Conway, 2002). Although we cannot confirm this because we are working in alert animals and do not have access to the anatomy, a location in $4 \mathrm{C} \beta$ is consistent with the depth at which these cells were found. Moreover, the multiunit hash at these depths had a buzzing quality on the audio monitor that is associated with the geniculate input layers (Livingstone and Hubel, 1984). The single-opponent responses we recorded might have been from afferent fibers arriving from the type I cells rather than from cortical cells. This would account for the size of their receptive fields, which is consistent with the size of LGN cell receptive fields, but the time-to-peak of the singleopponent cells, which was the same as that of the center of double-opponent red-green cells (Table 4; Fig. 12, open arrowhead), would argue against this: afferent fibers presumably would have a faster time course, closer to that of the LGN cells (Fig. 12, filled arrowhead). Cortical single-opponent neurons would constitute a logical intermediate cortical stage in the formation of double-opponent cells.

\section{Spatiotemporal maps of blue-yellow cells}

The retina and LGN process blue-yellow signals differently from the way they process red-green signals (Wiesel and Hubel, 1966; Dacey and Lee, 1994; Chichilnisky and Baylor, 1999; Hendry and Reid, 2000; Reid and Shapley, 2002), but discrete categories of red-green and blue-yellow cells have not been found in V1 (Lennie et al., 1990). Differences in processing of red-green and blueyellow signals were, however, apparent among the population of
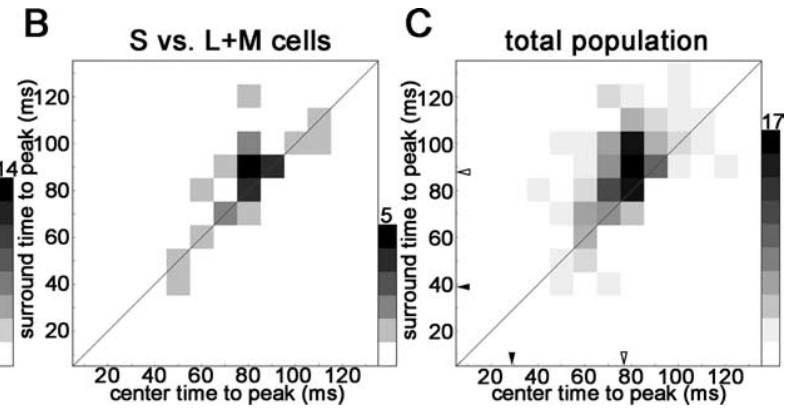

Time-to-peak of the excitatory response of the receptive-field centers and surrounds of cone-opponent neurons in ponses have been binned in $10 \mathrm{~ms}$ bins, according to their times-to-peak. The scale bar indicates the number of counts

Table 4. Time-to-peak response of receptive-field subregions ( \pm SE)

\begin{tabular}{lllllll}
\multicolumn{2}{c}{ Center time-to-peak (ms) } & & & \multicolumn{3}{l}{ Surround time-to-peak (ms) } \\
\cline { 1 - 2 } $\mathrm{L}$ & $\mathrm{M}$ & $\mathrm{S}$ & & $\mathrm{L}$ & $\mathrm{M}$ & $\mathrm{S}$ \\
\hline $73 \pm 1.3$ & $75 \pm 1.5$ & $84 \pm 2.3$ & & $84 \pm 2.0$ & $86 \pm 2.6$ & $95 \pm 4.1$ \\
$82 \pm 4.3$ & $81 \pm 3.3$ & $80 \pm 4.0$ & & $77 \pm 2.4$ & $88 \pm 5.6$ & $89 \pm 4.8$ \\
$69 \pm 3.4$ & $73 \pm 2.3$ & $83 \pm 5.8$ & & & \\
\hline
\end{tabular}

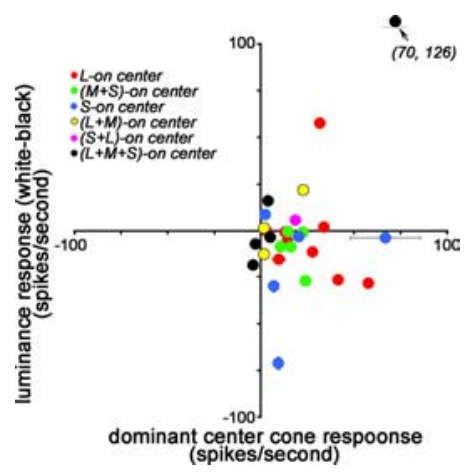

Figure 13. Responses of cone-opponent neurons to achromatic stimuli. Peak responses (method 2; see Materials and Methods) of the dominant center cone were compared with the white- black response at the receptive-field center. For $(L+M)-0 N$ cells, the average response to $L$ and $M$ was used. SDs of the background firing rate are shown if larger than the symbol size. Units are spikes per second.

V1 cone-opponent cells we studied. The ratio of L- and M-cone input was not consistent from cell to cell in the blue-yellow neurons but was for red-green neurons (Fig. 5) (see Results, Spatially opponent receptive-field structure in cone-opponent neurons). This imbalance is clear in the spatiotemporal movies of some blue-yellow cells (Fig. 15).

Complementarity in the response pattern between the + and - states of the L and M maps was lacking in the blue-OFF cell shown in Figure 15, which was suppressed by both the $\mathrm{L}+$ and $\mathrm{L}-$ stimuli at the peak reverse-correlation delay of the excitatory response to the $\mathrm{S}-$ stimulus $(76 \mathrm{~ms})$. The response to the $\mathrm{L}$ cone cannot be appreciated from the difference map, because the responses cancel. This neuron also responded to achromatic stimuli; the achromatic response was spatially most similar to the $\mathrm{M}$ response but faster (Fig. 15, bottom). These results are consistent 

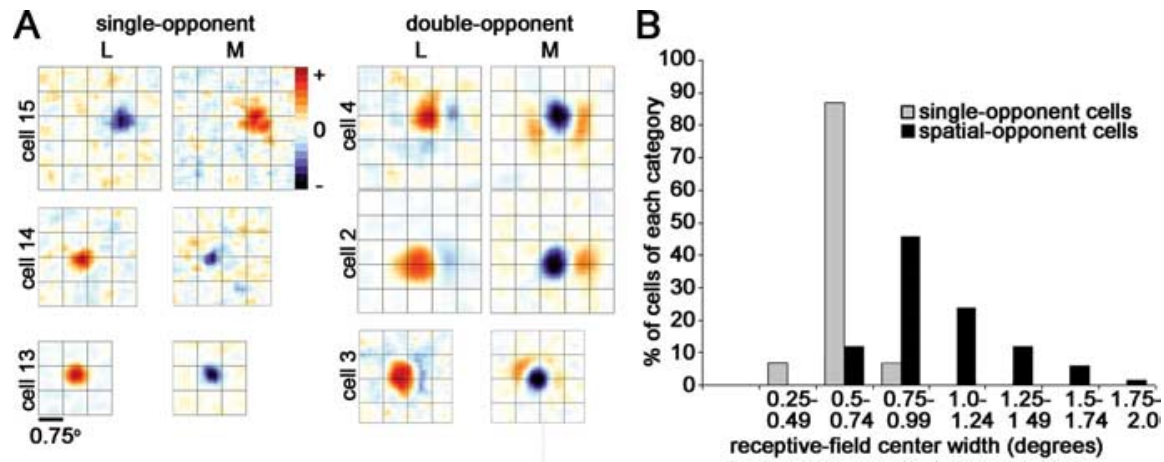

Figure 14. Receptive fields of single-opponent neurons in V1. $A$, Difference response maps to $\mathrm{L}$ and $\mathrm{M}$ cone-isolating stimuli of three single-opponent cells and three double-opponent cells. Response maps were taken at the peak reverse-correlation delay. Excitation $(+)$ is shown in red; suppression $(-)$ is shown in blue. The complete spatiotemporal movie of cell 13 is shown in supplemental Figure 4 (available at www.jneurosci.org as supplemental material). The overlying grid is $0.75^{\circ}$. B, Quantification of the receptive-field sizes of the population of single-opponent neurons and the receptive-field centers of spatial-opponent neurons (3/4-opponent neurons and double-opponent neurons combined). The single-opponent neurons have smaller receptive-field sizes ( $t$ test, $p<0.006)$.

with evidence showing nonlinear luminance responses in blueyellow neurons (Horwitz et al., 2005).

The $\mathrm{S}$ center response in the S-ON cells was often large (Fig. 6, cell 8) (supplemental Fig. 6, available at www.jneurosci.org as supplemental material), which is consistent with these cells receiving input from blue-yellow neurons in the LGN: blue-yellow neurons in the LGN and retina have larger receptive fields than red-green cells (Wiesel and Hubel, 1966; Dacey and Lee, 1994; Chichilnisky and Baylor, 1999; Reid and Shapley, 2002).

Only 2 of the 10 S-ON neurons were double-opponent, showing significant surround responses in both the $S$ map and the $\mathrm{L}$ (and/or M) map (Fig. 8B; Table 2); half (5 of 10) were $3 / 4$ opponent, showing significant surround responses in either the L or M map but not the $S$ map (supplemental Fig. 6, available at www.jneurosci.org as supplemental material). Red-green neurons, conversely, were more frequently double-opponent (41 of $66)$, showing $3 / 4$-opponency in only 13 of 66 cases $\left(\chi^{2}, 6.68\right.$; $p<$ 0.01 ). The high frequency of $3 / 4$-opponency in blue-yellow cells is accounted for by the fact that the S-cone input showed spatial structure less often than the $\mathrm{L}$ and $\mathrm{M}$ input in all cone-opponent neurons (see Results, Spatially opponent receptive-field structure in cone-opponent neurons). These results show that blue-yellow neurons have different spatiotemporal receptive-field properties than red-green neurons in four ways besides the constitution of the opponent systems: (1) blue-yellow cells did not receive balanced input from $\mathrm{M}$ and $\mathrm{L}$ cones (see Results, Absolute and relative strength of cone inputs to cone-opponent cells) (Fig. 5); (2) they did not show opponent responses (excitation vs suppression) to + and - of L and M stimuli, showing that blue-yellow neurons had nonlinear responses (see Results, Push-pull responses of cone-opponent neurons) (Figs. 3, 15); (3) they showed the same time course of response in the centers and surrounds (see Results, Time-course of the response of cone-opponent neurons) (Table 4); and (4) they were more often $3 / 4$-opponent than double-opponent.

\section{Rebound responses in cone-opponent neurons}

The temporal pattern of response of cone-opponent neurons was often biphasic, in both the center and surround. This can be appreciated from the STA histograms (Fig. 11), in which an initial excitation is followed by suppression or an initial suppression is followed by excitation.
This rebound response corresponds to the cessation of the stimulus and is clear in the spatiotemporal map of the example cell shown in Figure 16A (complete maps in supplemental Fig. 7, available at www.jneurosci.org as supplemental material). The first phase of the response was characterized by center excitation to $\mathrm{L}+$ and $\mathrm{M}-$, which peaked at $59 \mathrm{~ms}$, and surround excitation (within a crescentshaped region to the right of the center) to $\mathrm{L}-$ and $\mathrm{M}+$, which peaked at $76 \mathrm{~ms}$. The second phase of the response was characterized by the inverse pattern: rebound excitation of the center to $\mathrm{L}-$ and $\mathrm{M}+$, which peaked at $127 \mathrm{~ms}$, and rebound excitation of the surround to $\mathrm{L}+$ and $\mathrm{M}-$, which peaked at $144 \mathrm{~ms}$.

We quantified the rebound responses of the receptive-field center in the whole population of cone-opponent neurons (Fig. 16B). Red-green neurons showed rebound responses that matched the inversion of their initial responses: L-ON cells showed suppression to $\mathrm{L}$ and excitation to $\mathrm{M} ; \mathrm{M}-\mathrm{ON}$ cells showed excitation to $\mathrm{L}$ and suppression to $\mathrm{M}$. The biphasic responses of red-green neurons suggests that, on average, they respond to temporal color contrast, which is the case: responses of red-green double-opponent neurons to sequential oppositely colored spots can be predicted by the sum of the responses to each spot presented alone (Conway et al., 2002). The spatial color contrast of any scene is enhanced by temporal color contrast introduced by eye movements; these biphasic double-opponent neurons provide a neural mechanism that yokes spatial and temporal color contrast.

The temporal dynamics of the responses of blue-yellow cells were different from those of red-green cells (Table 4). Blueyellow neurons, on average, did not show responses matching the inversion of their initial responses: although S-ON cells showed rebound excitation to $\mathrm{L} / \mathrm{M}$ cones, they did not show significant rebound suppression to $\mathrm{S}$ cones; and $(\mathrm{L}+\mathrm{M})-\mathrm{ON}$ cells showed neither rebound suppression to $\mathrm{L} / \mathrm{M}$ cones nor rebound excitation to $S$ cones.

The measurements shown in Figure $16 B$ were obtained by subtracting the response to the - stimuli from the response to the + stimuli, but many neurons showed long-lasting suppression after the initial response, to both states of all stimuli, a response that would not be evident in these difference measurements. The neuron shown in Figure 2, for example, showed initial suppression to $\mathrm{L}-$ and $\mathrm{M}+$ center stimulation, which was never followed by rebound excitation (Fig. 2, L- histogram, black trace); the initial suppression was simply long lasting, outlasting the excitation to $\mathrm{L}+$ and $\mathrm{M}-$. The initial excitation to $\mathrm{L}+$ and $\mathrm{M}-$ was followed by a slight suppressive rebound, shown in the complete spatiotemporal map for this cell (supplemental Fig. 1, available at www.jneurosci.org as supplemental material). Supplemental Figure 6 (available at www.jneurosci.org as supplemental material) shows a blue-yellow neuron that also showed long-lasting suppression to both states of each cone stimulus. To examine these suppressive responses, we quantified the rebound responses to the two states separately (Fig. 17). Chromatically opponent rebound responses, like those of the cell in Figure 16A, are located in quadrants II and IV (Fig. 17). Many red-green neurons were located in quadrants II and IV, consistent with the significant average 

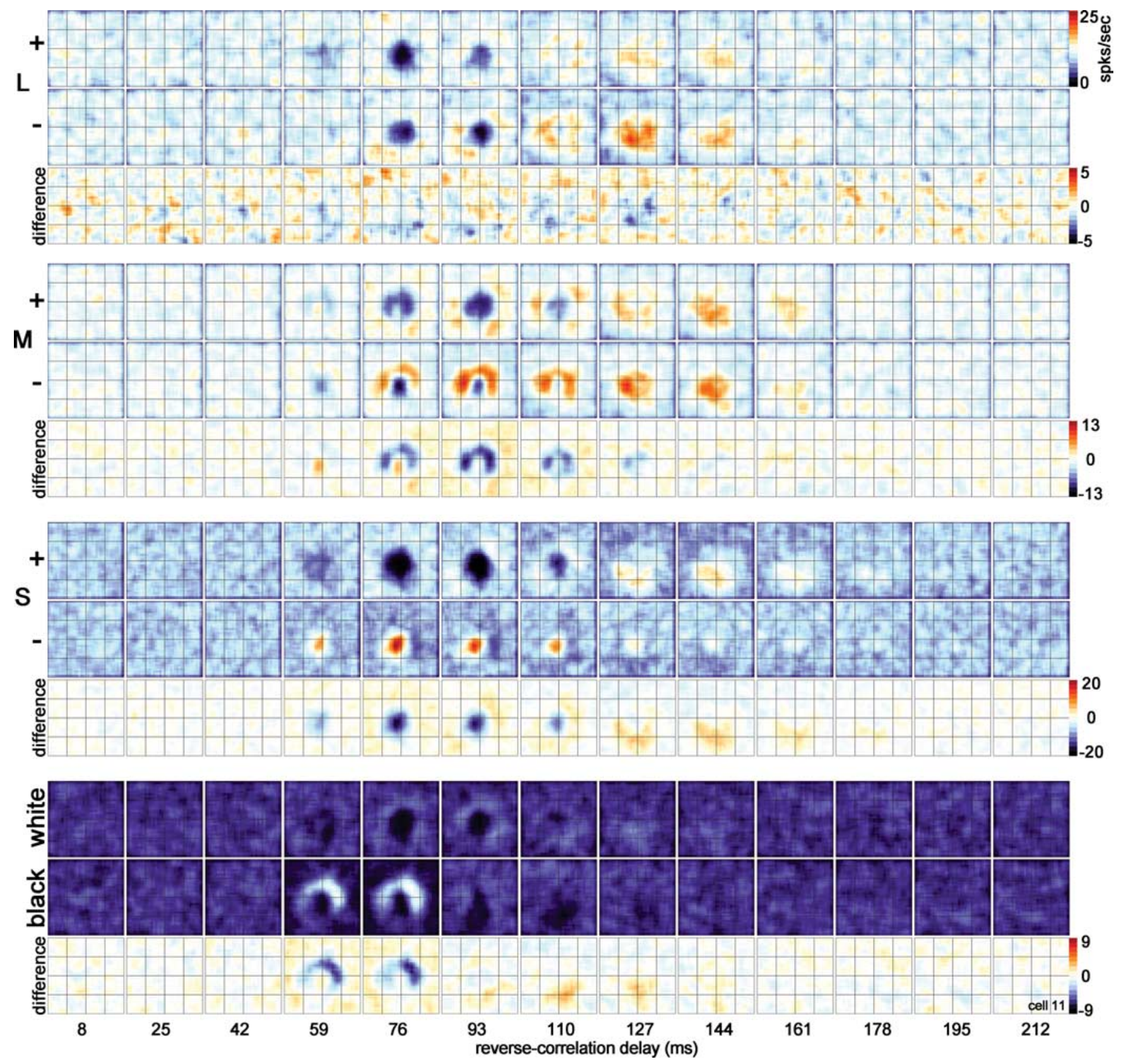

Figure 15. Spatiotemporal response of the cone inputs to a blue-yellow cell $[(L+M)-0 N-$-center]. The center showed pronounced suppression to $S+$ and weak excitation to $M+(59 \mathrm{~ms}$ in the difference maps). The $L$ cone did not show push-pull structure (both + and - maps show the same response pattern). A lack of push-pull in $L$ and/or $M$ maps was often found in blue-yellow neurons (Fig. 3). Stimulus duration of $34 \mathrm{~ms}$. Stimulus size of $0.64^{\circ}$. Other conventions as for Figure 10.

rebound response of red-green cells, but many neurons are located in quadrant III, indicating suppression to both states of the stimulus. That so many neurons show long-lasting suppression accounts for the large error bars of Figure 16B. These long-lasting rebound responses may be involved in chromatic adaptation.

\section{Discussion}

We determined the spatial and temporal organization of cone inputs to cone-opponent cells in alert macaque V1. Many coneopponent cells showed spatial opponency. These results, using stimuli with gray backgrounds, confirm results using stimuli with different colored backgrounds (Conway, 2001). Such "doubleopponent" receptive fields are ideal substrates for color con- stancy and color contrast (Hurlbert and Poggio, 1988; Dufort and Lumsden, 1991; Foster and Nascimento, 1994; Gegenfurtner, 2003; Hurlbert and Wolf, 2004), computations that likely involve V1 (Barbur et al., 2004) (but see Zeki et al., 1999). Some doubleopponent receptive fields were circularly symmetric, with round centers and doughnut-shaped surrounds, but most had round centers with crescent-shaped surrounds, or two parallel ovalshaped subfields. As a result, many showed weak orientation tuning. Double-opponent cells should respond optimally to color contrast (e.g., red next to green), which has been demonstrated, under neutral-adapting conditions, using adjacent patches of L+, M+, and S+ (Conway, 2001; Conway et al., 2002). 

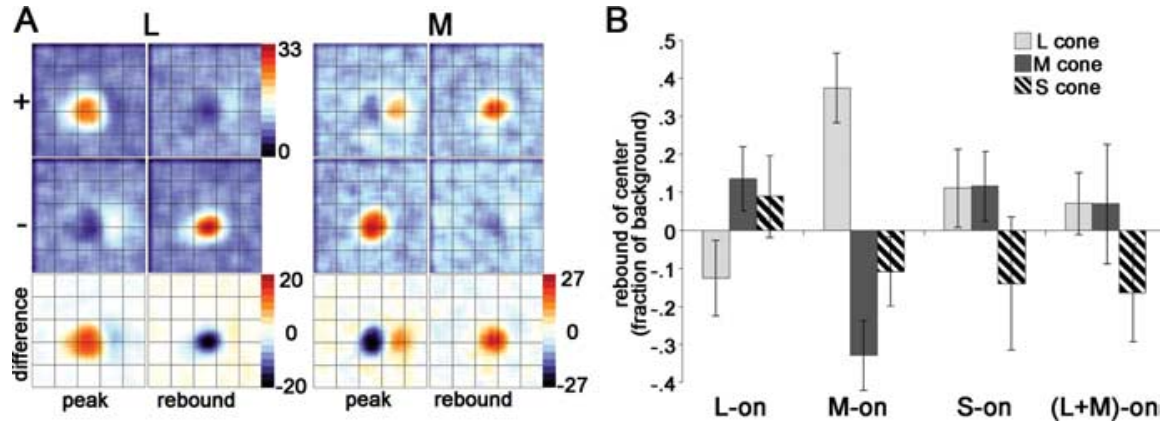

Figure 16. Rebound responses of cone-opponent cells. $\boldsymbol{A}$, Spatiotemporal response of the cone inputs to a red-ON-center cell that showed rebound responses in both center and surround. Stimulus duration of $51 \mathrm{~ms}$. Stimulus size of $0.48^{\circ}$. "peak" shows maps at $76 \mathrm{~ms}$ reverse-correlation delay; "rebound" shows maps at $127 \mathrm{~ms}$. Units are spikes per second. Other conventions as for Figure 10. The complete spatiotemporal response movie (supplemental Fig. 7, available at www.jneurosci.org as supplemental material) illustrates the interplay of the rebound response combined with the difference in timing of center and surround (Fig. 12). $B$, Average rebound responses to cone-isolating stimuli of the receptive-field center of L-ON-center cells, M-ON-center cells, $\mathrm{S}-\mathrm{ON}$-center cells, and $(\mathrm{L}+\mathrm{M})-\mathrm{ON}$-center cells. Responses are taken at the peak rebound response, after the cessation of the stimulus, and are determined by subtracting the - response from the + response, reported as a fraction of the baseline response. In neurons that showed no rebound response, the response at a reverse-correlation delay corresponding to the average time-torebound-peak for the population of cells was used. Red - green neurons ( $(-0 N$ and $M-O N)$ showed rebound responses: the rebound of $\mathrm{L}-\mathrm{ON}$ cells involved suppression by $\mathrm{L}$ cones and excitation by $\mathrm{M}+\mathrm{S}$ cones; the rebound of $\mathrm{M}-\mathrm{ON}$ cells showed excitation by $\mathrm{L}$ cones and suppression by $M+S$ cones. $S-O N$ neurons showed rebound responses to $L+M$ stimuli but not to $S$ stimuli; $(L+M)-0 N$ neurons did not show rebound responses to any cone stimulus. SEMs are shown.

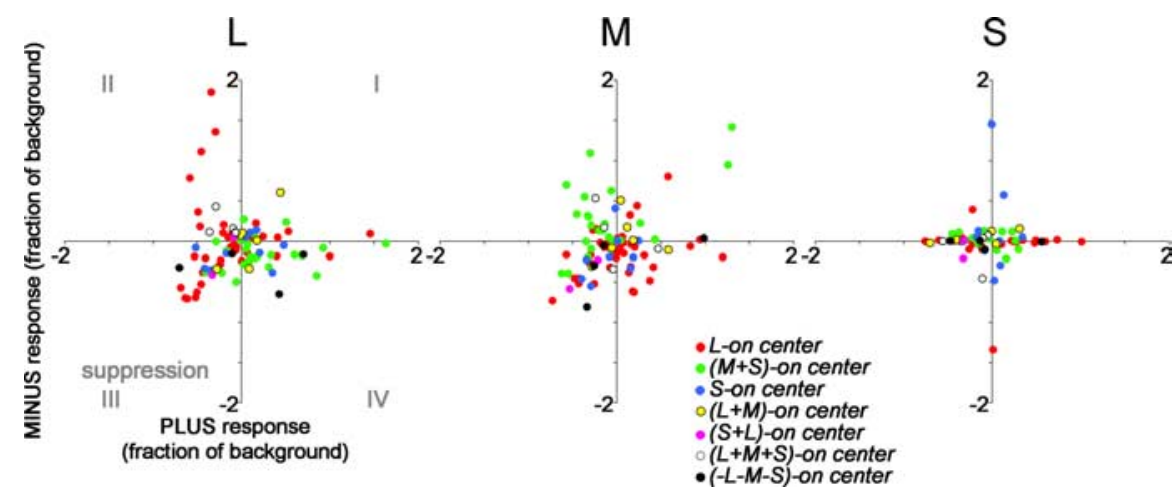

Figure 17. Rebound responses of cone-opponent neurons to + versus - states of the cone-isolating stimuli: L, left plot; $M$, middle plot; S, right plot. Responses calculated using Equation 4 (see Materials and Methods). Responses in quadrants II and IV show rebound responses, as expected from Figure 16: L-ON cells in quadrant II in the L plot and in quadrant IV in the M plot; $M-0 N$ cells in quadrant IV in the L plot and in quadrant II in the M plot. These neurons are capable of temporal color contrast. Other neurons showed suppressive rebound responses to both states of a given cone-isolating stimulus, depicted in quadrant III. S-cone rebound responses were weaker, shown by the clustering of the responses around the origin.

Most cone-opponent receptive fields were push-pull. Centers of red-ON neurons, for example, were not only excited by $\mathrm{L}$ increments (the push) but also suppressed by L decrements (the pull); they were also suppressed by $\mathrm{M}$ increments and excited by $\mathrm{M}$ decrements. That each neuron received both ON and OFF input may explain the observation that inactivating either the ON or OFF pathway in the retina has little impact on color processing (Schiller et al., 1986). Excitatory responses to decrements were slightly stronger than excitatory responses to increments; this is consistent with lower detection and discrimination thresholds for decrements. Most cone-opponent neurons also showed temporally biphasic responses, which could underlie temporal color contrast. Some neurons did not, showing instead long-lasting suppression after the initial response to all stimuli, a response that may contribute to chromatic adaptation.

\section{Red-green and blue-yellow cells}

Cone-opponent cells formed two populations, red-green (L vs $\mathrm{M}+\mathrm{S}$ ) and blue-yellow (S vs $\mathrm{L}+\mathrm{M})$. Several differences in the spatiotemporal organization of their cone inputs were seen. (1) Surrounds of blueyellow cells did not show later times-topeak relative to the centers, unlike the surrounds of red-green cells, which peaked 12 ms later than the centers. (2) The ratio of $\mathrm{L}$ and $\mathrm{M}$ inputs was not consistent for the population of blue-yellow cells, whereas for red-green cells it was. (3) Blue-yellow cells did not usually show pushpull responses to $\mathrm{L}$ and $\mathrm{M}$, whereas redgreen cells did. (4) Blue-yellow neurons were more often $3 / 4$-opponent, showing spatial opponency in only one opponent system, whereas red-green cells were more often double-opponent, showing spatial opponency in both opponent systems. (5) The responses of blue-yellow cells were not usually temporally biphasic, whereas those of red-green cells were.

As a population, V1 neurons do not form discrete color categories (Lennie et al., 1990). The results here show that those V1 neurons specifically specialized for color (by virtue of cone opponency) do. This suggests that the cortex maintains a distinction between subcortical red-green and blue-yellow channels (Dacey and Lee, 1994; Martin et al., 1997; Hendry and Reid, 2000; Chatterjee and Callaway, 2003). The cortex must do some mixing of subcortical channels, however, to account for the S-cone input to red-green cells; LGN red-green cells apparently do not receive S input (Derrington et al., 1984). S responses of red-green cells aligned with $\mathrm{M}$ responses, promoting the idea that these cells are actually red-cyan.

LGN cell responses do not predict unique hues (Wuerger et al., 2005). It remains to be seen whether cortical redcyan and blue-yellow cells come closer. An evaluation of this should be based on the population averages, however, because perceptual coordinates exaggerate small differences in cone weights (Conway and Livingstone, 2005). Like LGN cells (Romney et al., 2005), cortical cone-opponent responses probably include most colors, except purple, when the responses are transformed into perceptual coordinates. Whether the brain interprets the responses of the two classes of coneopponent cells as red-cyan and blue-yellow axes defining perceptual color space or assigns perceptual significance to the variability among single cone-opponent neurons is unknown.

\section{Double-opponent and complex-equiluminant cells}

Like simple cells, a defining feature of double-opponent cells is spatial receptive-field structure (Daw, 1968; Michael, 1978). Unlike simple cells, the receptive-field organization of doubleopponent cells is not defined by luminance. The center of a red-ON cell was excited by both $\mathrm{L}+$ (luminance $\mathrm{ON}$ ) and $\mathrm{M}-$ (luminance OFF), and its surround was excited by both $\mathrm{M}+$ $(\mathrm{ON})$ and $\mathrm{L}-(\mathrm{OFF})$, as if two luminance simple cells, each defined by a single cone input, were combined in a way that super- 
imposed the ON subregion of one input with the OFF subregion of the other.

Double-opponent neurons should therefore respond to stimuli defined only by color contrast, with no luminance contrast, and they do (Conway et al., 2002). Indeed, bandpass spatial frequency tuning to equiluminant colored gratings has been proposed as "a major test" of doubleopponency (Shapley and Hawken, 2002; Solomon et al., 2004). Although this test probes a necessary feature of doubleopponency, it is by itself insufficient to prove double-opponency: neurons could show bandpass spatial frequency tuning to equiluminant stimuli without having spatial receptive-field structure, just as complex cells can show orientation tuning without having spatially structured receptive fields. In fact, more than half of V1 cells, many more than we found to be double-opponent, show bandpass spatial frequency tuning to equiluminant colored gratings (Gouras and Kruger, 1979; Thorell et al., 1984; Hubel and Livingstone, 1990b; Lennie et al., 1990; Johnson et al., 2001). This strong equiluminance response has also been shown with functional magnetic resonance imaging (Schluppeck and Engel, 2002; Conway and Tsao, 2006) and is probably attributed to complex-equiluminance cells (Fig. 18). Unlike double-opponent cells, complex-equiluminance cells would be able to use LGN color signals to detect colored boundaries regardless of the configuration of the colors forming the boundary, which may help in defeating camouflage and may explain psychophysical experiments revealing color channels that are sharply tuned for spatial frequency (Bradley et al., 1988). Double-opponent cells, conversely, seem good candidates for the spatial color calculations that underlie hue. That color vision is subserved by double-opponent cells is further supported by the coarse size of their receptive fields and the small percentage of them in the cortex, which matches the poor spatial resolution of color vision (Livingstone and Hubel, 1987). Finally, double-opponent cells show contrast-invariant receptivefield structure (Conway, 2001, 2006), a criterion for color coding that is not shown by the majority of cortical cells (Solomon and Lennie, 2005).

\section{Wiring of double-opponent cells}

The likely inputs to blue-yellow double-opponent cells are type II cells. The scale of double-opponent receptive fields suggests that the center receives input from one type II cell and each hotspot in the surround, from a different type II cell. The wiring must be more complicated, however, because the locations of $\mathrm{L}$ and $\mathrm{M}$ surrounds were sometimes not aligned (Fig. 6, cell 10), suggesting that blue-yellow cells sample the signals from $\mathrm{L}$ and $\mathrm{M}$ cones independently.

Type II cells have also been proposed as building blocks for red-green double-opponent cells (Hubel and Livingstone, 1990b; Calkins and Sterling, 1999), but no definitive red-green type II cells have been described, leading to alternative models, like that of Billock (1991), which use type I cells, the same cells used to build complex-equiluminance cells (Fig. 18). Doubleopponent and complex-equiluminant cells could arise from the same input distribution in the same way that complex cells and simple cells in the cat can be generated from the same input by shifting the threshold nonlinearity (Mechler and Ringach, 2002; Priebe et al., 2004).

Billock's model makes three predictions. First, it predicts that double-opponent cells have larger receptive fields than LGN cells. They do. Double-opponent receptive-field centers were on average $1^{\circ}$ wide, with surrounds an additional $0.7^{\circ}$ wide. Type I cells at the same eccentricity, measured using similar techniques, are $0.24-0.5^{\circ}$ wide (Reid and Shapley, 2002). Second, it predicts that 
double-opponent cells should have spatially offset surrounds. Centers and surrounds were offset by $0.63^{\circ}$, more than half the width of the average receptive-field center. Finally, the model predicts that double-opponent neurons will respond to luminance; many do. Luminance responses show that the cone inputs to any given cell may not be balanced, although as a population, at least for the red-green cells, they are. Luminance responses may enhance chromatic signals (Horwitz et al., 2005) and contribute to the binding of form and color (Billock and Tsou, 2004).

The lack of circular symmetry of real cone-opponent neurons supports the prediction that receptive-field center and surround are constructed by sampling different pools of type I cells; receptive-field hot spots may simply reflect uneven sampling of inputs. That center and surround are constructed independently is supported by two additional observations on red-green cells: first, there was little correlation between the extent (or strength) of the receptive-field center and the extent (or strength) of the surround; and second, centers and surrounds had different time courses. However, the model should be adjusted slightly, to accommodate the push-pull organization, the S-cone responses of red-green cells, and the possibility that singleopponent cortical cells are an intermediate cortical stage in wiring double-opponent cells.

\section{References}

Barbur JL, DeCunha D, Williams CB, Plant G (2004) Studies of instantaneous colour constancy machanisms in human vision. J Electron Imaging 13:15-28.

Baylor DA, Nunn BJ, Schnapf JL (1987) Spectral sensitivity of cones of the monkey Macaca fascicularis. J Physiol (Lond) 390:145-160.

Billock VA (1991) The relationship between simple and double opponent cells. Vision Res 31:33-42.

Billock VA (1995) Cortical simple cells can extract achromatic information from the multiplexed chromatic and achromatic signals in the parvocellular pathway. Vision Res 35:2359-2369.

Billock VA, Tsou BH (2004) A role for cortical crosstalk in the binding problem: stimulus-driven correlations that link color, form, and motion. J Cogn Neurosci 16:1036-1048.

Bowen RW, Pokorny J, Smith VC (1989) Sawtooth contrast sensitivity: decrements have the edge. Vision Res 29:1501-1509.

Boynton RM, Ikeda M, Stiles WS (1964) Interactions among chromatic mechanisms as inferred from positive and negative increment thresholds. Vision Res 4:87-117.

Bradley A, Switkes E, DeValois K (1988) Orientation and spatial frequency selectivity of adaptation to color and luminance gratings. Vision Res 28:841-856.

Buchsbaum G, Bloch O (2002) Color categories revealed by non-negative matrix factorization of Munsell color spectra. Vision Res 42:559-563.

Burkhardt DA, Gottesman J, Kersten D, Legge GE (1984) Symmetry and constancy in the perception of negative and positive luminance contrast. J Opt Soc Am A 1:309-316.

Calkins DJ, Sterling P (1999) Evidence that circuits for spatial and color vision segregate at the first retinal synapse. Neuron 24:313-321.

Caywood MS, Willmore B, Tolhurst DJ (2004) Independent components of color natural scenes resemble V1 neurons in their spatial and color tuning. J Neurophysiol 91:2859-2873.

Chatterjee S, Callaway EM (2003) Parallel colour-opponent pathways to primary visual cortex. Nature 426:668-671.

Chichilnisky EJ, Baylor DA (1999) Receptive-field microstructure of blueyellow ganglion cells in primate retina. Nat Neurosci 2:889-893.

Chichilnisky EJ, Kalmar RS (2002) Functional asymmetries in ON and OFF ganglion cells of primate retina. J Neurosci 22:2737-2747.

Chichilnisky EJ, Wandell BA (1996) Seeing gray through the ON and OFF pathways. Vis Neurosci 13:591-596.

Conway BR (2001) Spatial structure of cone inputs to color cells in alert macaque primary visual cortex (V-1). J Neurosci 21:2768-2783.

Conway BR (2002) Neural mechanisms of color vision. Boston: Kluwer Academic.

Conway BR (2006) Stable receptive field structure of color neurons in pri- mary visual cortex under adapting and non-adapting conditions. Presented at the Third European Conference on Colour in Graphics, Imaging, and Vision of the Society for Imaging Science and Technology, Leeds, United Kingdom, June.

Conway BR, Livingstone MS (2003) Space-time maps and two-bar interactions of different classes of direction-selective cells in macaque V-1. J Neurophysiol 89:2726-2742.

Conway BR, Livingstone MS (2005) A different point of hue. Proc Natl Acad Sci USA 102:10761-10762.

Conway BR, Tsao DY (2006) Color architecture in alert macaque cortex revealed by fMRI. Cereb Cortex 16:1604-1613.

Conway BR, Hubel DH, Livingstone MS (2002) Color contrast in macaque V1. Cereb Cortex 12:915-925.

Cottaris NP (2003) Artifacts in spatiochromatic stimuli due to variations in preretinal absorption and axial chromatic aberration: implications for color physiology. J Opt Soc Am A Opt Image Sci Vis 20:1694-1713.

Cottaris NP, De Valois RL (1998) Temporal dynamics of chromatic tuning in macaque primary visual cortex. Nature 395:896-900.

Dacey DM, Lee BB (1994) The "blue-on" opponent pathway in primate retina originates from a distinct bistratified ganglion cell type. Nature 367:731-735.

Daw N (1968) Goldfish retina: organization for simultaneous color contrast. Science 158:942-944.

De Monasterio FM, Gouras P (1975) Functional properties of ganglion cells of the rhesus monkey retina. J Physiol (Lond) 251:167-195.

De Valois RL, Smith CJ, Kitai ST, Karoly AJ (1958) Response of single cells in monkey lateral genculate nucleus to monochromatic light. Science 127:238-239.

De Valois RL, Morgan HC, Polson MC, Mead WR, Hull EM (1974) Psychophysical studies of monkey vision. I. Macaque luminosity and color vision tests. Vision Res 14:53-67.

Derrington AM, Krauskopf J, Lennie P (1984) Chromatic mechanisms in lateral geniculate nucleus of macaque. J Physiol (Lond) 357:241-265.

Doi E, Inui T, Lee TW, Wachtler T, Sejnowski TJ (2003) Spatiochromatic receptive field properties derived from information-theoretic analyses of cone mosaic responses to natural scenes. Neural Comput 15:397-417.

Dufort PA, Lumsden CJ (1991) Color categorization and color constancy in a neural network model of V4. Biol Cybern 65:293-303.

Ferster D (1988) Spatially opponent excitation and inhibition in simple cells of the cat visual cortex. J Neurosci 8:1172-1180.

Ferster D (1994) Linearity of synaptic interactions in the assembly of receptive fields in cat visual cortex. Curr Opin Neurobiol 4:563-568.

Foster DH, Nascimento SMC (1994) Relational colour constancy from invariant cone-excitation ratios. Proc R Soc Lond B Biol Sci 257:115-121.

Friedman HS, Zhou H, von der Heydt R (2003) The coding of uniform colour figures in monkey visual cortex. J Physiol (Lond) 548:593-613.

Gegenfurtner KR (2003) Cortical mechanisms of colour vision. Nat Rev Neurosci 4:563-572.

Gouras P (1974) Opponent-colour cells in different layers of foveal striate cortex. J Physiol (Lond) 238:583-602.

Gouras P, Kruger J (1979) Responses of cells in foveal visual cortex of the monkey to pure color contrast. J Neurophysiol (Lond) 42:850-860.

Hendry SH, Reid RC (2000) The koniocellular pathway in primate vision. Annu Rev Neurosci 23:127-153.

Hirsch JA, Alonso JM, Reid RC, Martinez LM (1998) Synaptic integration in striate cortical simple cells. J Neurosci 18:9517-9528.

Horwitz GD, Chichilnisky EJ, Albright TD (2005) Blue-yellow signals are enhanced by spatiotemporal luminance contrast in macaque V1. J Neurophysiol 93:2263-2278.

Hubel D, Livingstone M (1990a) Color puzzles. Cold Spring Harb Symp Quant Biol 55:643-649.

Hubel DH (1957) Tungsten microelectrode for recording from single units. Science 125:549.

Hubel DH, Livingstone MS (1990b) Color and contrast sensitivity in the lateral geniculate body and primary visual cortex of the macaque monkey. J Neurosci 10:2223-2237.

Hubel DH, Wiesel TN (1962) Receptive fields, binocular interaction and functional architecture in the cat's visual cortex. J Physiol (Lond) 160:106-154.

Hubel DH, Wiesel TN (1968) Receptive fields and functional architecture of monkey striate cortex. J Physiol (Lond) 195:215-243. 
Hurlbert A, Wolf K (2004) Color contrast: a contributory mechanism to color constancy. Prog Brain Res 144:147-160.

Hurlbert AC, Poggio TA (1988) Synthesizing a color algorithm from examples. Science 239:482-485.

Johnson EN, Hawken MJ, Shapley R (2001) The spatial transformation of color in the primary visual cortex of the macaque monkey. Nat Neurosci 4:409-416.

Johnson EN, Hawken MJ, Shapley R (2004) Cone inputs in macaque primary visual cortex. J Neurophysiol 91:2501-2514.

Jones JP, Palmer LA (1987) The two-dimensional spatial structure of simple receptive fields in cat striate cortex. J Neurophysiol 58:1187-1211.

Judge SJ, Richmond BJ, Chu FC (1980) Implantation of magnetic search coils for measurement of eye position: an improved method. Vision Res 20:535-538.

Krauskopf J (1980) Discrimination and detection of changes in luminance. Vision Res 20:671-677.

Kremers J, Lee BB, Pokorny J, Smith VC (1993) Responses of macaque ganglion cells and human observers to compound periodic waveforms. Vision Res 33:1997-2011.

Land EH (1977) The retinex theory of color vision. Sci Am 237:108-128.

Lee BB (1996) Receptive field structure in the primate retina. Vision Res 36:631-644.

Lennie P, D’Zmura M (1988) Mechanisms of color vision. Crit Rev Neurobiol 3:333-400.

Lennie P, Krauskopf J, Sclar G (1990) Chromatic mechanisms in striate cortex of macaque. J Neurosci 10:649-669.

Livingstone MS, Conway BR (2003) Substructure of direction-selective receptive fields in macaque V1. J Neurophysiol 89:2743-2759.

Livingstone MS, Hubel DH (1984) Anatomy and physiology of a color system in the primate visual cortex. J Neurosci 4:309-356.

Livingstone MS, Hubel DH (1987) Psychophysical evidence for separate channels for the perception of form, color, movement, and depth. J Neurosci 7:3416-3468.

Livingstone MS, Freeman DC, Hubel DH (1996) Visual responses in V1 of freely viewing monkeys. Cold Spring Harb Symp Quant Biol 61:27-37.

Logothetis NK, Schiller PH, Charles ER, Hurlbert AC (1990) Perceptual deficits and the activity of the color-opponent and broad-band pathways at isoluminance. Science 247:214-217.

Martin PR, White AJ, Goodchild AK, Wilder HD, Sefton AE (1997) Evidence that blue-on cells are part of the third geniculocortical pathway in primates. Eur J Neurosci 9:1536-1541.

Martinez LM, Wang Q, Reid RC, Pillai C, Alonso JM, Sommer FT, Hirsch JA (2005) Receptive field structure varies with layer in the primary visual cortex. Nat Neurosci 8:372-379.

Mechler F, Ringach DL (2002) On the classification of simple and complex cells. Vision Res 42:1017-1033.

Michael CR (1978) Color vision mechanisms in monkey striate cortex: dual-opponent cells with concentric receptive fields. J Neurophysiol 41:572-588.

Pack CC, Berezovskii VK, Born RT (2001) Dynamic properties of neurons in cortical area MT in alert and anaesthetized macaque monkeys. Nature 414:905-908.

Priebe NJ, Mechler F, Carandini M, Ferster D (2004) The contribution of spike threshold to the dichotomy of cortical simple and complex cells. Nat Neurosci 7:1113-1122.
Reid RC, Shapley RM (2002) Space and time maps of cone photoreceptor signals in macaque lateral geniculate nucleus. J Neurosci 22:6158-6175.

Rodieck RW (1965) Quantitative analysis of cat retinal ganglion cell response to visual stimuli. Vision Res 5:583-601.

Romney AK, D'Andade RG, Indow T (2005) The distribution of response spectra in the lateral geniculate nucleus compared with reflectance spectra of Munsell color chips. Proc Natl Acad Sci USA 102:9720-9725.

Sandell JH, Gross CG, Bornstein MH (1979) Color categories in macaques. J Comp Physiol Psychol 93:626-635.

Schiller PH, Finlay BL, Volman SF (1976) Quantitative studies of single-cell properties in monkey striate cortex. I. Spatiotemporal organization of receptive fields. J Neurophysiol 39:1288-1319.

Schiller PH, Sandell JH, Maunsell JH (1986) Functions of the ON and OFF channels of the visual system. Nature 322:824-825.

Schluppeck D, Engel SA (2002) Color opponent neurons in V1: a review and model reconciling results from imaging and single-unit recording. J Vis 2:480-492.

Shapley R, Hawken M (2002) Neural mechanisms for color perception in the primary visual cortex. Curr Opin Neurobiol 12:426-432.

Smithson HE, Mollon JD (2004) Is the S-opponent chromatic sub-system sluggish? Vision Res 44:2919-2929.

Solomon SG, Lennie P (2005) Chromatic gain controls in visual cortical neurons. J Neurosci 25:4779-4792.

Solomon SG, Peirce JW, Lennie P (2004) The impact of suppressive surrounds on chromatic properties of cortical neurons. J Neurosci 24:148-160.

Stockman A, Sharpe LT (2000) The spectral sensitivities of the middle- and long-wavelength-sensitive cones derived from measurements in observers of known genotype. Vision Res 40:1711-1737.

Stockman A, MacLeod DI, Johnson NE (1993) Spectral sensitivities of the human cones. J Opt Soc Am A Opt Image Sci Vis 10:2491-2521.

Tailor DR, Finkel LH, Buchsbaum G (2000) Color-opponent receptive fields derived from independent component analysis of natural images. Vision Res 40:2671-2676.

Thorell LG, De Valois RL, Albrecht DG (1984) Spatial mapping of monkey V1 cells with pure color and luminance stimuli. Vision Res 24:751-769.

Tsao DY, Conway BR, Livingstone MS (2003) Receptive fields of disparitytuned simple cells in macaque V1. Neuron 38:103-114.

Wachtler T, Sejnowski TJ, Albright TD (2003) Representation of color stimuli in awake macaque primary visual cortex. Neuron 37:681-691.

Walraven J (1977) Colour signals from incremental and decremental light stimuli. Vision Res 17:71-76.

Whittle P (1986) Increments and decrements: luminance discrimination. Vision Res 26:1677-1691.

Wiesel TN, Hubel DH (1966) Spatial and chromatic interactions in the lateral geniculate body of the rhesus monkey. J Neurophysiol 29:1115-1156.

Wuerger SM, Atkinson P, Cropper S (2005) The cone inputs to the uniquehue mechanisms. Vision Res 45:3210-3223.

Young RA (1987) The Gaussian derivative model for spatial vision. I. Retinal mechanisms. Spat Vis 2:273-293.

Zeki S, Aglioti S, McKeefry D, Berlucchi G (1999) The neurological basis of conscious color perception in a blind patient. Proc Natl Acad Sci USA 96:14124-14129. 